\title{
Diagnósticos de Enfermagem identificados entre usuários do Centro de Atenção Psicossocial Álcool e Outras Drogas do Município de Caucaia-CE
}

\author{
Nursing Diagnoses identified among users of the Psychosocial Attention Center for Alcohol and \\ Other Drugs in the City of Caucaia-CE \\ Diagnósticos de Enfermería identificados entre usuarios del Centro de Atención Psicosocial de \\ Alcohol y Otras Drogas en el Municipio de Caucaia-CE
}

Recebido: 19/01/2021 | Revisado: 25/01/2021 | Aceito: 28/01/2021 | Publicado: 06/02/2021

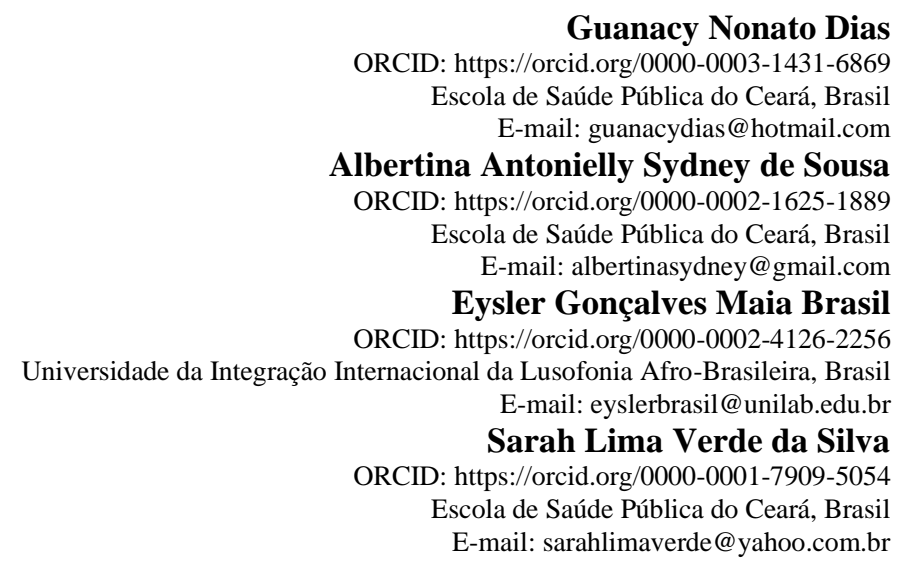

\begin{abstract}
Resumo
Objetivo: identificar os principais Diagnósticos de Enfermagem entre os usuários de um Centro de Atenção Psicossocial aos Usuários de Álcool e Outras Drogas do Município de Caucaia-CE. Metodologia: estudo exploratório-descritivo, documental, quantitativo realizado no CAPS AD de Caucaia-CE. Dentre os 1020 prontuários ativos, após o cálculo amostral, elegeram-se 200 prontuários para análise. Os dados foram coletados entre dezembro de 2019 e abril de 2020 , por meio de instrumento previamente elaborado, analisados por estatística descritiva simples e com base na NANDA-I (2018-2020) para a identificação dos principais Diagnósticos de Enfermagem; e discutidos com base na literatura pertinente. Resultados: O perfil dos usuários registrados era majoritariamente masculino, de adultos jovens, solteiros, com ensino fundamental incompleto, desempenhando algum tipo de ocupação, sendo o álcool a substância de preferência. Foram identificados 37 diagnósticos de Enfermagem com predominância dos com foco no problema, seguido dos de promoção da saúde. Com relação à análise dos diagnósticos de risco e com foco no problema, emergiram três subcategorias: 1) Problemas de enfrentamento e na autopercepção; 2) Problemas autodirigidos; e 3) Problemas biológicos, físicos, psicológicos e sociais. O abuso de substância despontou como elemento relacionado ou de risco para grande parte desses enunciados. Conclusão: Tendo em vista a complexidade que envolve o cuidado de Enfermagem no âmbito da Saúde Mental, aponta-se que o levantamento dos Diagnósticos de Enfermagem nesse cenário é uma ferramenta primordial para entender os indivíduos em suas singularidades e delinear intervenções alinhadas às suas necessidades de cuidado.
\end{abstract}

Palavras-chave: Serviços de saúde mental; Álcool; Drogas; Diagnósticos de enfermagem.

\begin{abstract}
Objective: to identify the main Nursing Diagnoses among users of a Psychosocial Care Center for Users of Alcohol and Other Drugs in Caucaia-CE. Methodology: exploratory-descriptive, documentary, quantitative study carried out at CAPS AD in Caucaia-CE. Among the 1020 active medical records, after the sample calculation, 200 medical records were chosen for analysis. Data were collected between December 2019 and April 2020, using a previously developed instrument, analyzed by simple descriptive statistics and based on NANDA-I (2018-2020) for the identification of the main Nursing Diagnoses; and discussed based on the relevant literature. Results: The users registered profile was mostly male, young adults, single, with incomplete elementary education, performing some type of occupation, being the alcohol as preferred substance. 37 Nursing diagnoses were identified, with predominance of those focused on the
\end{abstract}


problem, followed by health promotion diagnoses. Regarding the analysis of risk diagnoses and focusing on the problem diagnoses, three subcategories emerged: 1) Problems of coping and self-perception; 2) Self-directed problems; and 3) Biological, physical, psychological and social problems. Substance abuse emerged as a related or risky element for most of these statements. Conclusion: Considering the complexity that involves nursing care in the context of Mental Health, it is pointed out that the survey of Nursing Diagnoses in this scenario is a primary tool to understand individuals in their singularities and outline interventions aligned to their nursing care needs.

Keywords: Mental health services; Alcohol; Drugs; Nursing diagnoses.

\section{Resumen}

Objetivo: identificar los principales Diagnósticos de Enfermería en usuarios de un Centro de Atención Psicosocial a Usuarios de Alcohol y Otras Drogas del Municipio de Caucaia-CE. Metodología: estudio exploratorio-descriptivo, documental, cuantitativo realizado en CAPS AD en Caucaia-CE. Entre los 1020 registros médicos activos, después del cálculo de la muestra, se eligieron 200 registros médicos para análisis. Los datos fueron recolectados entre diciembre de 2019 y abril de 2020, utilizando un instrumento previamente elaborado, analizados mediante estadística descriptiva simple y con base en NANDA-I (2018-2020) para la identificación de los principales Diagnósticos de Enfermería; y discutidos sobre la base de la literatura relevante. Resultados: El perfil de usuarios registrados fue mayoritariamente masculino, adultos jóvenes, solteros, con educación básica incompleta, realizando algún tipo de ocupación, siendo el alcohol la sustancia preferida. Se identificaron 37 diagnósticos de enfermería, con predominio de los enfocados al problema, seguidos de la promoción de la salud. Respecto al análisis de los diagnósticos de riesgo y focalización en el problema, surgieron tres subcategorías: 1) Problemas de afrontamiento y autopercepción; 2) Problemas autodirigidos; y 3) Problemas biológicos, físicos, psicológicos y sociales. El abuso de sustancias surgió como un elemento relacionado o de riesgo para la mayoría de estas declaraciones. Conclusión: Ante la complejidad que envuelve el cuidado de enfermería en Salud Mental, se señala que la encuesta de Diagnósticos de Enfermería en este escenario es una herramienta primaria para comprender a los individuos en sus singularidades y perfilar intervenciones alineadas a sus necesidades de enfermería.

Palabras clave: Servicios de salud mental; Alcohol; Drogas; Diagnósticos de enfermería.

\section{Introdução}

O movimento da Reforma Psiquiátrica brasileira preconiza a permuta gradativa do modelo manicomial pela criação de uma rede de serviços substitutivos territorializados, de base comunitária, cujo tratamento seja sustentado na Atenção Psicossocial. O movimento busca viabilizar às pessoas com transtorno mental um novo ambiente na sociedade, respeitando as idiossincrasias dentro do seu meio, no intuito de motivar sua cidadania baseado na instituição de novas práticas terapêuticas inclusivas (Berlink, Magtaz, \& Teixeira, 2008; Pereira, Machado, \& Nascimento, 2008).

A proposta de desconstrução do modelo manicomial e das práticas segregadoras frente às situações de sofrimento psíquico foi mobilizada por diversos atores sociais do campo da saúde mental como profissionais, usuários e gestores, e teve sua consolidação através da Lei 10.2016 de 06 de abril de 2001, conhecida como Lei da Reforma Psiquiátrica, que destaca dentre suas recomendações, o direito da pessoa em sofrimento psíquico ser tratada, preferencialmente, em serviços comunitários de saúde mental (Brasil, 2001).

Neste contexto, coloca-se em relevo o papel fundamental dos Centros de Atenção Psicossocial (CAPS), que se caracterizam por ser um serviço ambulatorial de atenção diária que funcionam segundo a lógica do território, de modo substitutivo ao hospital psiquiátrico, realizando o acolhimento e a atenção às pessoas com transtornos mentais graves e persistentes (BRASIL, 2001). Segundo os dispositivos legais, os Centros de Atenção Psicossocial poderão constituir-se nas seguintes modalidades de serviços: CAPS I, II e III (geral); CAPS i II (infantil); e CAPS ad II, III e IV (álcool e drogas), definidos por ordem crescente de porte/complexidade e abrangência populacional (Brasil, 2002, 2012, 2017).

Logo, os CAPS são vistos como um serviço que se diferencia das estruturas tradicionais e que se orienta pela ampliação do espaço de participação social do sujeito que sofre, pela democratização das ações, pela não segregação do adoecimento psíquico e pela valorização da subjetividade, com base nas ações multiprofissionais (Tavares \& Sousa, 2009). 
A multidisciplinaridade sob a ótica da interdisciplinaridade alicerça o desenvolvimento das atividades no CAPS, destacando-se o papel do enfermeiro como agente do cuidado em saúde mental. Para tanto, coloca-se o humanismo como o princípio basilar do cuidado de Enfermagem, ou seja, a transposição do olhar clínico para um olhar compreensivo, embasado no desenvolvimento do diálogo, do acolhimento e do afeto entre enfermeiro e usuário, representando um desafio para o cuidado integral (Almeida, Moraes, \& Peres, 2009; Marcolan \& Castro, 2013).

A Lei $n^{\circ} 7.498$ de 25 de junho de 1986, refere sobre a regulamentação do exercício da Enfermagem bem como as atividades que são específicas do enfermeiro (Brasil, 1986), e afirma o direito à participação como membro da equipe de saúde; nessa conjuntura, a Portaria Ministerial n $336 / 02$ apresenta a obrigatoriedade do profissional enfermeiro na equipe do CAPS, conferindo a importância de sua presença nesta modalidade de serviço. Ressalta-se, ainda, que para os CAPS II e III, e CAPS $\mathrm{AD}$, é preconizado que o enfermeiro tenha formação em saúde mental (Brasil, 2002).

No âmbito específico do CAPS, o enfermeiro desenvolve ações de natureza inter- e transdisciplinar, voltadas principalmente à promoção de saúde e bem estar e baseadas no acolhimento e fortalecimento de vínculos de confiança. Trabalhando na perspectiva individual e coletiva, as quais englobam usuário, família e comunidade, o enfermeiro desenvolve práticas mais amplas como educação em saúde mental; manutenção e gerenciamento do ambiente terapêutico e dos cuidados individuais em todos os ciclos vitais; realização de ações comunitárias para a saúde mental; e participação na elaboração de políticas de saúde mental envolvendo a Rede de Atenção Psicossocial (RAPS) (Lacchini et al., 2011).

De acordo com a Resolução n ${ }^{\circ}$ 599/2018 do Conselho Federal de Enfermagem, que aprova a Norma Técnica para Atuação da Equipe de Enfermagem em Saúde Mental e Psiquiatria, é competência do enfermeiro: cuidados de Enfermagem de maior qualificação técnica e que necessitem alicerces científicos adequados e capacidade de tomar providências imediatas, bem como planejamento, coordenação, organização, direção e avaliação do serviço de Enfermagem nos serviços de saúde mental e psiquiatria. Traz ainda como atribuição específica realizar Processo de Enfermagem por meio da Consulta de Enfermagem em saúde mental com o intuito de viabilizar a Sistematização da Assistência de Enfermagem (Brasil, 2018).

A Consulta de Enfermagem (CE), aliada à proposta de elaboração do PTS na perspectiva interdisciplinar, pode prover ao usuário, família e coletividade um cuidado pautado na integralidade. É considerada um instrumento metodológico que orienta o cuidado e a documentação da prática profissional de Enfermagem e está formada por cinco etapas interrelacionadas, interdependentes e recorrentes, a saber: Coleta de dados de Enfermagem (ou Histórico de Enfermagem), Diagnóstico de Enfermagem, Planejamento de Enfermagem, Implementação e Avaliação de Enfermagem. A identificação desses estágios e o desenvolvimento racional do seguimento são úteis para o processo de pensamento crítico e raciocínio clínico do enfermeiro (Brasil, 2009; Cossa \& Almeida, 2012).

A Consulta de Enfermagem como atividade privativa do enfermeiro consta na Lei $n^{\circ} 7.498$, de 25 de junho de 1986 (Brasil, 1986) e é definida pela Resolução COFEN 358/2009 em seu $\S 2^{\circ}$ que, quando exercido em entidades prestadoras de serviços ambulatoriais de saúde, domicílios, escolas, associações comunitárias, entre outros, o Processo de Saúde de Enfermagem coincide ao usualmente intitulado nesses recintos como Consulta de Enfermagem (Brasil, 2009). Neste processo, salienta-se a importância da realização criteriosa das etapas de Coleta de dados de Enfermagem (ou Histórico de Enfermagem) e Diagnóstico de Enfermagem para prover um plano de cuidados eficiente.

A NANDA International (NANDA-I) disponibiliza uma nomenclatura padronizada de diagnósticos de Enfermagem e apresenta todos eles em um esquema classificatório, mais especificamente uma taxonomia. Logo, o diagnóstico de Enfermagem é o alicerce para a escolha de intervenções de Enfermagem a fim de atingir resultados pelos quais os enfermeiros são encarregados. Ou seja, eles são aplicados para estabelecer o plano de cuidados pertinente para o paciente, direcionando os resultados e as intervenções (etapa do Planejamento de Enfermagem) e viabilizam uma linguagem uniforme para uso em prontuários eletrônicos, propiciando clareza na comunicação da equipe de saúde, bem como na coleta de dados para o otimização constante dos cuidados 
ao paciente (NANDA-I, 2018).

Segundo a taxonomia da NANDA-I (2018), o Diagnóstico de Enfermagem (DE) é o julgamento clínico sobre uma resposta humana a condições de saúde/processos de vida, ou a uma vulnerabilidade para essa resposta, por um indivíduo, família, grupo ou comunidade. O diagnóstico de enfermagem constitui a base para a escolha de intervenções de enfermagem para alcançar resultados pelos quais respondem os enfermeiros.

Encontram-se elencados em Domínios (grupos maiores) e Classes (subgrupos dentro de cada domínio), onde podem ser classificados: 1) com foco no problema: sobre uma resposta humana indesejada a condições de saúde/processos de vida; 2) de risco: sobre a vulnerabilidade para desenvolvimento de uma resposta humana indesejada a condições de saúde/processos de vida; e 3) de promoção da saúde: sobre motivação e desejo de aumentar o bem-estar e concretizar o potencial de saúde humana, onde as respostas são expressas por uma disposição para melhorar comportamentos específicos de saúde e podem ser utilizadas em qualquer condição de saúde.

Dentre as classificações de DE, há uma estrutura de registro para cada um deles, baseado no formato PES (acrônimo para problema (P), etiologia/fatores relacionados (E) e sinais/sintomas/características definidoras (S)). Desta forma, para DE com foco no problema, tem-se a estrutura título diagnóstico + fatores etiológicos (fatores relacionados) + características definidoras (sinais e sintomas); para DE de risco, não há fatores relacionados (etiológicos), uma vez que se está identificando a vulnerabilidade de um paciente a um potencial problema, logo, tem-se título diagnóstico + fator(es) de risco; e para DE de promoção da saúde, como estes não exigem um fator relacionado, pode não haver "relacionado a" em sua redação; em vez disso, as características definidoras são apresentadas como evidência do desejo do paciente de melhorar seu estado de saúde atual ou o reconhecimento pelo enfermeiro da existência de uma oportunidade de promoção da saúde.

Entretanto, não obstante a evidenciada importância do estabelecimento dos Diagnósticos de Enfermagem no contexto legal do exercício da SAE e Consulta de Enfermagem (CE), essa sistemática do cuidado não ocorrem no CAPS AD do Município de Caucaia com a amplitude designada. Na dinâmica assistencial do equipamento, houve tentativas de implementação da CE, as quais ocorreram de forma descontínua e sem solidificação dos processos. Diante desse cenário, com o intuito de se estabelecer a CE como uma metodologia de trabalho constante no equipamento citado, surgiu a necessidade de se identificar os principais diagnósticos de Enfermagem que possibilitariam um eixo para a escolha de ações e intervenções de Enfermagem voltadas àqueles usuários.

Tendo em vista a necessidade de apropriação do exercício legal da Enfermagem no campo da saúde mental, a realização da CE pautada em uma linguagem diagnóstica consagrada permite a orientação do cuidado, bem como a documentação da prática profissional, reforçando a contribuição da Enfermagem na atenção à saúde da população e aumentando a visibilidade e o reconhecimento da equipe de Enfermagem na atenção psicossocial. Além disso, permite modificações de contextos e a percepção de fenômenos relacionados aos processos de cuidar, abrindo caminho para construção de operacionalizações cada vez mais pertinentes ao exercício legal da profissão no âmbito da Saúde Mental.

Nesse contexto, objetivou-se identificar os principais Diagnósticos de Enfermagem entre os usuários do CAPS AD do Município de Caucaia-CE.

\section{Metodologia}

Trata-se de um estudo exploratório-descritivo, documental, com abordagem quantitativa realizado em um Centro de Atenção Psicossocial aos Usuários de Álcool e Outras Drogas (CAPS AD) do Município de Caucaia-CE. De acordo com Pereira, Shitsuka, Parreira e Shitsuka (2018) a pesquisa quantitativa envolve o uso de métodos e técnicas de coleta de dados, bem como de sua análise, que permitem a expressão de certos fenômenos por meio de números, porcentagens e estatísticas.

O equipamento realiza cerca de 100 atendimentos por semana entre acolhimentos e consultas marcadas. Presta serviço 
à comunidade sob a óptica interdisciplinar e de reabilitação psicossocial. É realizada prática da assistência oferecendo atendimentos individuais e em grupos, oficinas terapêuticas e de criação. No tocante à Assistência de Enfermagem, é realizado acolhimento, triagem, administração e orientação sobre o uso da medicação, Grupo de Redução de Danos, Grupo de Tabagismo e Consulta de Enfermagem. Ressalta-se a família como alicerce providencial do tratamento, possuindo atendimento específico (grupal ou individual) e livre acesso.

A população do estudo estava composta por 1020 prontuários ativos. Os mesmos são considerados ativos quando possuem pelo menos um atendimento da equipe multiprofissional no período de um ano. Após a aplicação da fórmula para o cálculo amostral, elegeram-se 200 prontuários para o estudo, os quais foram escolhidos aleatoriamente para análise.

Os dados foram coletados entre dezembro de 2019 e abril de 2020, por meio de instrumento previamente elaborado contendo questões referentes aos dados socioeconômicos (gênero, idade, estado civil, escolaridade e profissão), bem como tipo de substância psicoativa, tratamentos anteriores, comorbidades e implicações biopsicossociais para embasar a identificação dos principais Diagnósticos de Enfermagem segundo a NANDA-I (2018-2020), com suas características definidoras e fatores relacionados ou fatores de risco.

A apreensão dos Diagnósticos de Enfermagem, a partir dos dados coletados no instrumento, foi realizada seguindo-se o raciocínio clínico-diagnóstico (apreensão, julgamento e pensamento crítico). Após a escolha dos DE, os mesmos foram organizados nas categorias empíricas: 1) Diagnósticos de Enfermagem com foco no problema e de risco, composta pelas subcategorias temáticas: Problemas de enfrentamento e na autopercepção; Problemas autodirigidos; Problemas biológicos, físicos, psicológicos e sociais; e 2) Diagnósticos de Promoção da Saúde.

Os dados foram organizados no programa Microsoft Excel $^{\circledR}$, analisados por meio de estatística descritiva simples e com base na NANDA-I (2018-2020) e discutidos com base na literatura pertinente.

O estudo foi realizado após apreciação e autorização pelo CAPS AD e pelo Comitê de Ética em Pesquisa da Escola de Saúde Pública do Governo do Estado do Ceará (parecer n $n^{\circ}$ 3.766.649). Além disso, foram respeitados os preceitos éticos da Resolução no 466/2012 que regulamenta a pesquisa envolvendo seres humanos.

\section{Resultados}

\subsection{Caracterização do perfil dos usuários do CAPS AD}

A amostra analisada foi constituída, majoritariamente, por homens (78\%) com uma média de 41 anos de idade, solteiros (59\%) e com nível de escolaridade predominante inferior a nove anos completos de estudo (37,5\%). Quanto à ocupação, 49\% dos indivíduos desempenhavam alguma atividade formal (16,5\%) ou autônoma (32,5\%) e 36\% deles estavam desempregados.

Acerca do tipo de substância psicoativa utilizada pelos usuários tem-se o consumo de álcool de maneira isolada (38,5\%), seguido do uso de tabaco (29\%). Em relação aos tratamentos anteriores, os dispositivos utilizados pelos usuários foram: comunidades terapêuticas (17,5\%), CAPS (12,5\%), rede de urgência e emergência (10,5\%) e Atenção Primária em Saúde (5\%). Em menor expressão, outras entidades como Alcoólicos Anônimos (AA) e Narcóticos Anônimos (NA) (3,0\%) foram mencionadas.

Finalmente, no tocante às implicações biopsicossociais relacionadas ao uso/abuso de substâncias psicoativas entre os usuários deste estudo, mencionam-se como conflitos os: familiares $(25,5 \%)$, sociais $(17,0 \%)$, trabalhistas $(9,5 \%)$ e judiciais $(7,0 \%)$.

\subsection{Principais Diagnósticos de Enfermagem identificados}

De acordo com a análise dos 200 prontuários, a aplicação do raciocínio diagnóstico face aos dados coletados permitiu identificar, com base na NANDA-I (2018-2020), 37 diagnósticos de Enfermagem divididos em: com foco no problema (56,8\%); 
de risco $(18,9 \%)$ e de promoção da saúde $(24,3 \%)$, os quais se encontram divididos em domínios, conforme ilustra a Figura 1 abaixo.

Figura 1. Distribuição dos Diagnósticos de Enfermagem identificados, segundo os domínios apresentados pela NANDA-I (2018-2020). Caucaia-CE, 2020.

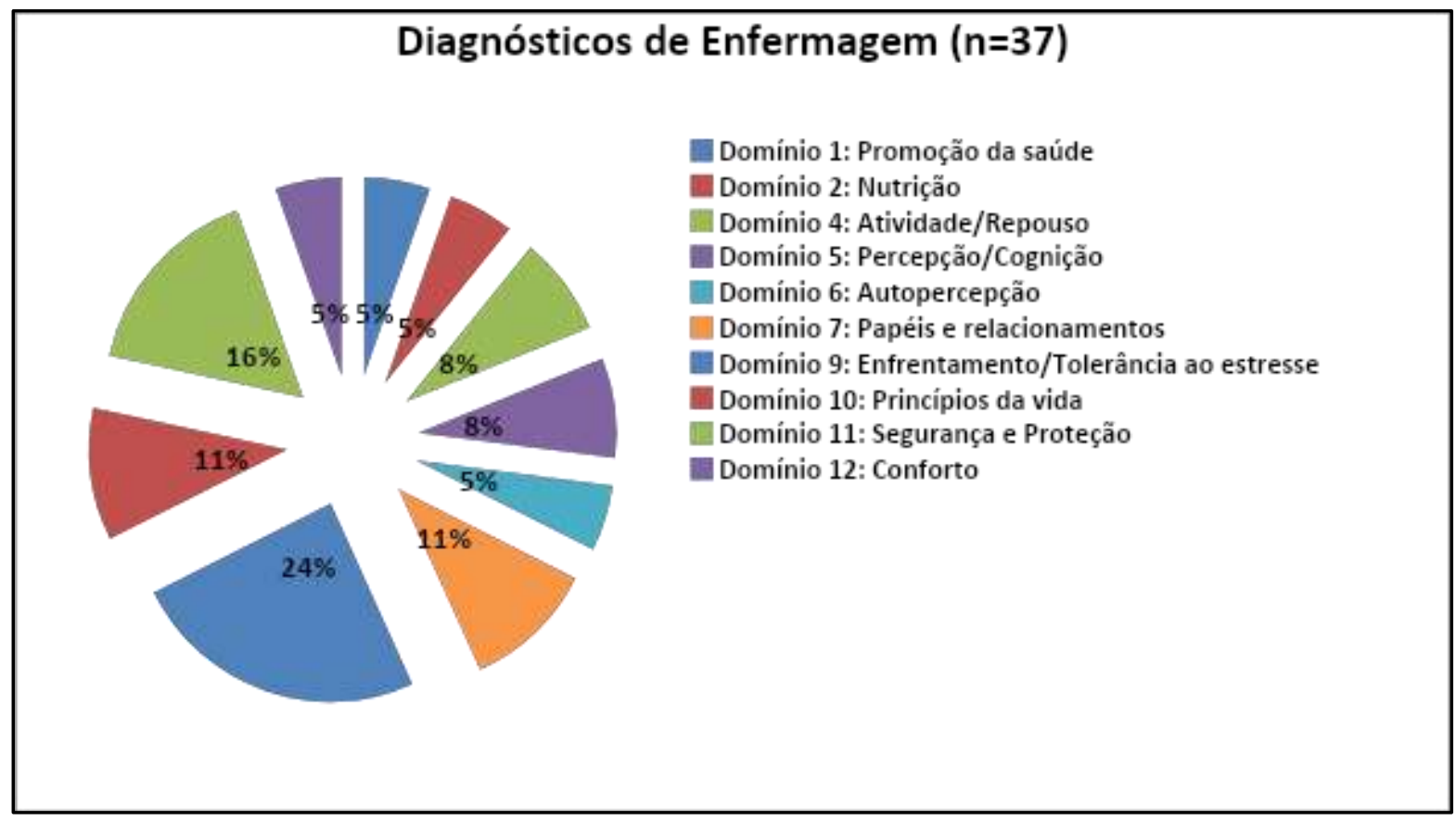

Fonte: Dados primários do estudo (2020).

A seguir, são apresentados detalhadamente os diagnósticos de Enfermagem organizados em domínios e com seus respectivos fatores relacionados e características definidoras (para a estrutura de diagnósticos com foco no problema ou de promoção da saúde) e fatores de risco (para a estrutura de diagnósticos de risco). Outros dois quesitos contemplados 1) populações em risco: grupos de pessoas que partilham alguma característica que faz cada membro ser suscetível a determinada resposta humana, como características demográficas, história de saúde/familiar, estágios de crescimento/desenvolvimento ou exposição a determinados eventos/experiências; e 2) condições associadas: diagnósticos médicos, lesões, procedimentos, dispositivos médicos ou agentes farmacêuticos, as quais não são independentemente modificáveis pelo enfermeiro, embora possam dar apoio à precisão nos diagnósticos de enfermagem; são elencados à caracterização quando pertinentes.

Para o Domínio 1 (Promoção da saúde) foram elencados dois títulos diagnósticos Comportamento de saúde propenso a risco ( $\mathrm{n}=169 ; 84,5 \%)$ e Disposição para controle da saúde melhorado $(\mathrm{n}=122 ; 61 \%)$. Em relação ao Domínio 2 (Nutrição) foram identificados os títulos diagnósticos Nutrição desequilibrada: menor do que as necessidades corporais ( $\mathrm{n}=31 ; 15,5 \%)$ e Risco de função hepática prejudicada $(n=77 ; \mathrm{f}=38,5 \%)$. A caracterização dos Diagnósticos referentes a esses domínios se encontra disposta no Quadro 1 a seguir. 
Quadro 1. Caracterização dos Diagnósticos de Enfermagem referentes aos domínios Promoção da Saúde e Nutrição identificados no estudo. Caucaia-CE, 2020.

\begin{tabular}{|l|l|}
\hline \multicolumn{2}{|c|}{ Comportamento de saúde propenso a risco } \\
\hline \multicolumn{1}{|c|}{ Fatores relacionados } & \multicolumn{1}{|c|}{ Características definidoras } \\
\hline $\begin{array}{l}|c| \\
\text { - Ansiedade social; } \\
\text { - Apoio social insuficiente; } \\
\text { - Baixa autoeficácia; }\end{array}$ & - Abuso de substâncias; \\
- Estressores. & - Falha em alçar um senso de controle ideal; \\
\hline Populações em risco: Desfavorecido economicamente e história familiar de alcoolismo. \\
\hline \multicolumn{2}{|c|}{ Disposição para controle da saúde melhorado } \\
\hline \multicolumn{2}{|c|}{ Características definidoras } \\
\hline $\begin{array}{l}\text { Expressão do desejo de melhorar: 1) as escolhas da vida diária para alcançar metas; 2) o controle de fatores } \\
\text { de risco e; 3) o controle de regimes prescritos. }\end{array}$ \\
\hline
\end{tabular}

\begin{tabular}{|l|l|}
\hline \multicolumn{2}{|c|}{ DOMÍNIO 2: Nutrição } \\
\hline Nutrição desequilibrada: menor do que as necessidades corporais \\
\hline \multicolumn{1}{|c|}{ Fator relacionado } & \multicolumn{1}{c|}{ Características definidoras } \\
\hline - Ingestão alimentar insuficiente & $\begin{array}{l}\text { - Interesse insuficiente pelos alimentos; } \\
\text { - Ingestão de alimentos menor que a ingestão diária } \\
\text { recomendada (IDR). }\end{array}$ \\
\hline Populações em risco: Desfavorecido economicamente. \\
\hline \multicolumn{2}{|c|}{ Risco de função hepática prejudicada } \\
\hline Fator de risco: Abuso de substância (álcool)
\end{tabular}

Fonte: Dados primários do estudo (2020).

Concernente ao Domínio 4 (Atividade/Repouso) os títulos diagnósticos Autonegligência (n=99; 49,5\%); Disposição para melhora do autocuidado $(n=89 ; 44,5 \%)$ e Insônia $(n=48 ; 24 \%)$ foram identificados entre os usuários. No Domínio 5 (Percepção/Cognição), identificaram-se os enunciados diagnósticos Disposição para conhecimento melhorado (n=67; 33,5\%), Controle emocional lábil $(n=40 ; 20 \%)$ e Confusão aguda $(n=39 ; 19,5 \%)$. A caracterização dos Diagnósticos referentes a esses domínios está disposta no Quadro 2 a seguir. 
Quadro 2. Caracterização dos Diagnósticos de Enfermagem referentes aos domínios Atividade/Repouso e Percepção/Cognição identificados no estudo. Caucaia-CE, 2020.

\begin{tabular}{|c|c|}
\hline \multicolumn{2}{|c|}{ DOMÍNIO 4: Atividade/Repouso } \\
\hline \multicolumn{2}{|c|}{ Autonegligência } \\
\hline Fatores relacionados & Características definidoras \\
\hline Abuso de substâncias. & Falta de adesão a atividades de saúde. \\
\hline \multicolumn{2}{|c|}{ Disposição para melhora do autocuidado } \\
\hline \multicolumn{2}{|c|}{ Características definidoras } \\
\hline \multicolumn{2}{|c|}{$\begin{array}{l}\text { Expressão do desejo de aumentar a independência na vida e de aumentar o conhecimento sobre estratégias } \\
\text { de autocuidado. }\end{array}$} \\
\hline \multicolumn{2}{|c|}{ Insônia } \\
\hline Fatores relacionados & Características definidoras \\
\hline $\begin{array}{l}\text { - Consumo de álcool; } \\
\text { - Ansiedade; } \\
\text { - Estressores. }\end{array}$ & Alteração no padrão de sono. \\
\hline
\end{tabular}

\begin{tabular}{|c|c|}
\hline \multicolumn{2}{|c|}{ DOMÍNIO 5: Percepção/Cognição } \\
\hline \multicolumn{2}{|c|}{ Disposição para conhecimento melhorado } \\
\hline \multicolumn{2}{|c|}{ Característica definidora: Expressão do desejo de melhorar a aprendizagem. } \\
\hline \multicolumn{2}{|c|}{ Controle emocional lábil } \\
\hline Fator relacionado & Características definidoras \\
\hline $\begin{array}{l}\text { - Abuso de substâncias } \\
\text { - Estressores. }\end{array}$ & $\begin{array}{l}\text { - Ausência de contato visual; } \\
\text { - Choro incontrolável. }\end{array}$ \\
\hline \multicolumn{2}{|c|}{ Confusão aguda } \\
\hline Fator relacionado & Características definidoras \\
\hline - Abuso de substância. & $\begin{array}{l}\text { - Alteração no nível de consciência; } \\
\text { - Alucinações; } \\
\text { - Inquietação; } \\
\text { - Alteração na função psicomotora. }\end{array}$ \\
\hline Populações em risco: sexo masculino & \\
\hline Delirium. & \\
\hline
\end{tabular}

Fonte: Dados primários do estudo (2020).

Em relação ao Domínio 6 (Autopercepção) foram identificados os títulos diagnósticos Baixa autoestima situacional $(\mathrm{n}=71 ; 35,5 \%)$ e Risco de dignidade humana comprometida ( $\mathrm{n}=36 ; 18 \%)$. No Domínio 7 (Papéis e relacionamentos), identificaram-se os títulos diagnósticos Processos familiares disfuncionais ( $\mathrm{n}=60 ; 30 \%)$; Desempenho de papel ineficaz ( $\mathrm{n}=26$; 13\%); Disposição para processos familiares melhorados ( $\mathrm{n}=9 ; 4,5 \%)$; e, em menor expressão, Relacionamento ineficaz ( $\mathrm{n}=3$; 1,5\%). A caracterização dos Diagnósticos referentes a esses domínios está apresentada no Quadro 3 a seguir. 
Quadro 3. Caracterização dos Diagnósticos de Enfermagem referentes aos domínios Autopercepção e Papéis e relacionamentos identificados no estudo. Caucaia-CE, 2020.

\begin{tabular}{|c|c|}
\hline \multicolumn{2}{|c|}{ DOMÍNIO 6: Autopercepção } \\
\hline \multicolumn{2}{|c|}{ Baixa autoestima situacional } \\
\hline Fatores relacionados & Características definidoras \\
\hline $\begin{array}{l}\text { - Alteração no papel social; } \\
\text { - Autoexpectativas não realistas; } \\
\text { - Padrão de desamparo. }\end{array}$ & $\begin{array}{l}\text { - Ausência de propósito; } \\
\text { - Comportamento indeciso; } \\
\text { - Comportamento não assertivo; } \\
\text { - Desamparo; } \\
\text { - Subestimação da capacidade de lidar com a } \\
\text { situação. }\end{array}$ \\
\hline \multicolumn{2}{|c|}{ Risco de dignidade humana comprometida } \\
\hline \multicolumn{2}{|c|}{ Fator de risco: Estigmatização e tratamento desumano. } \\
\hline \multicolumn{2}{|c|}{ DOMÍNIO 7: Papéis e relacionamentos } \\
\hline \multicolumn{2}{|c|}{ Processos familiares disfuncionais } \\
\hline Fatores relacionados & Características definidoras \\
\hline $\begin{array}{l}\text { - Abuso de substâncias; } \\
\text { - Pessoa adicta. }\end{array}$ & $\begin{array}{l}\text { - Abuso verbal de pai/mãe; } \\
\text { - Culpar a si mesmo; } \\
\text { - Dificuldade com transição de ciclo vital; } \\
\text { - Abandono; } \\
\text { - Depressão; } \\
\text { - Desesperança; } \\
\text { - Fracasso; } \\
\text { - Frustração; } \\
\text { - Insegurança; } \\
\text { - Rejeição; } \\
\text { - Sofrimento; } \\
\text { - Solidão; } \\
\text { - Vulnerabilidade. }\end{array}$ \\
\hline \multicolumn{2}{|c|}{ Populações em risco: Desfavorecido economicamente e história familiar de abuso de substâncias. } \\
\hline \multicolumn{2}{|c|}{ Desempenho de papel ineficaz } \\
\hline Fatores relacionados & Características definidoras \\
\hline $\begin{array}{l}\text { - Abuso de substâncias; } \\
\text { - Estressores. }\end{array}$ & $\begin{array}{l}\text { - Alteração na percepção do papel; } \\
\text { - Autocontrole insuficiente; } \\
\text { - Sentimento de impotência. }\end{array}$ \\
\hline \multicolumn{2}{|c|}{ Disposição para processos familiares melhorados } \\
\hline \multicolumn{2}{|c|}{ Característica definidora } \\
\hline \multicolumn{2}{|c|}{ Expressão do desejo de aumentar o respeito pelos membros da família. } \\
\hline \multicolumn{2}{|c|}{ Relacionamento ineficaz } \\
\hline Fatores relacionados & Características definidoras \\
\hline $\begin{array}{l}\text { - Abuso de substâncias; } \\
\text { - Estressores. }\end{array}$ & $\begin{array}{l}\text { - Comunicação insatisfatória entre os parceiros; } \\
\text { - Insatisfação no atendimento das necessidades } \\
\text { emocionais entre os parceiros. }\end{array}$ \\
\hline
\end{tabular}

Fonte: Dados primários do estudo (2020).

No âmbito do Domínio 9 (Enfrentamento/Tolerância ao estresse), foi identificado o maior número de DE (nove). Destacam-se os títulos diagnósticos Síndrome de abstinência de substâncias aguda (n=90; 45\%) e Ansiedade (n=45; 22,5\%).

Em seguida, têm-se os títulos representativos de problemas, principalmente no que tange à capacidade do usuário em lidar com situações conflituosas que permeiam o contexto de uso/abuso de substâncias: Enfrentamento ineficaz (n=23; 11,5\%), Sentimento de impotência ( $n=13 ; 6,5 \%)$; Resiliência prejudicada ( $n=8 ; 4 \%)$; e Regulação do humor prejudicada (n=7; 3,5\%). Em outra vertente, observam-se os títulos referentes à promoção da saúde por meio de inferências ao desejo de melhoria/resolução dos problemas supracitados; destacam-se: Disposição para enfrentamento melhorado (n=6; 3\%); Disposição para resiliência melhorada $(n=5 ; 2,5 \%)$; e Disposição para poder melhorado $(n=5 ; 2,5 \%)$. A caracterização dos Diagnósticos referentes a esse domínio se encontra disposta no Quadro 4 a seguir. 
Quadro 4. Caracterização dos Diagnósticos de Enfermagem referentes ao domínio Enfrentamento/Tolerância ao estresse identificados no estudo. Caucaia-CE, 2020.

\begin{tabular}{|c|c|}
\hline \multicolumn{2}{|c|}{ DOMÍNIO 9: Enfrentamento/Tolerância ao estresse } \\
\hline \multicolumn{2}{|c|}{ Síndrome de abstinência de substâncias aguda } \\
\hline Fatores relacionados & Características definidoras \\
\hline $\begin{array}{l}\text { - Desenvolvimento de dependência do álcool ou de } \\
\text { outra substância aditiva; } \\
\text { - Interrupção repentina de uma substância aditiva; } \\
\text { - Uso pesado de substância aditiva ao longo do } \\
\text { tempo. }\end{array}$ & $\begin{array}{l}\text { - Ansiedade; } \\
\text { - Confusão aguda; } \\
\text { - Distúrbio no padrão de sono; } \\
\text { - Náusea; } \\
\text { - Risco de lesão. }\end{array}$ \\
\hline \multicolumn{2}{|c|}{ Ansiedade } \\
\hline Fatores relacionados & Características definidoras \\
\hline $\begin{array}{l}\text { - Abuso de substâncias; } \\
\text { - Estressores. }\end{array}$ & $\begin{array}{l}\text { - Inquietação; } \\
\text { - Insônia; } \\
\text { - Medo; } \\
\text { - Nervosismo; } \\
\text { - Sofrimento; } \\
\text { - Aumento da tensão; } \\
\text { - Tremores; } \\
\text { - Aumento da frequência cardíaca; } \\
\text { - Aumento da pressão arterial; } \\
\text { - Boca seca; } \\
\text { - Palpitações cardíacas; } \\
\text { - Alterações no padrão do sono; } \\
\text { - Fadiga; } \\
\text { - Náusea; } \\
\text { - Confusão; } \\
\text { - Preocupação. }\end{array}$ \\
\hline \multicolumn{2}{|c|}{ Enfrentamento ineficaz } \\
\hline Fatores relacionados & Características definidoras \\
\hline $\begin{array}{l}\text { - Confiança inadequada na capacidade de lidar com } \\
\text { uma situação; } \\
\text { - Sensação de controle insuficiente. }\end{array}$ & $\begin{array}{l}\text { - Abuso de substâncias; } \\
\text { - Comportamento destrutivo em relação a si mesmo; } \\
\text { - Incapacidade de lidar com uma situação. }\end{array}$ \\
\hline \multicolumn{2}{|c|}{ Sentimento de impotência } \\
\hline Fatores relacionados & Características definidoras \\
\hline $\begin{array}{l}\text { - Ansiedade; } \\
\text { - Dor; } \\
\text { - Estigmatização. }\end{array}$ & $\begin{array}{l}\text { - Dependência; } \\
\text { - Depressão; } \\
\text { - Frustração quanto à incapacidade de realizar } \\
\text { atividades anteriores; } \\
\text { - Sensação de controle insuficiente. }\end{array}$ \\
\hline \multicolumn{2}{|c|}{ Resiliência prejudicada } \\
\hline Fatores relacionados & Características definidoras \\
\hline $\begin{array}{l}\text { - Abuso de substância; } \\
\text { - Controle insuficiente dos impulsos; } \\
\text { - Dinâmica familiar perturbada. }\end{array}$ & $\begin{array}{l}\text { - Culpa; } \\
\text { - Depressão; } \\
\text { - Estado de saúde prejudicado; } \\
\text { - Estratégias de enfrentamento ineficazes. }\end{array}$ \\
\hline \multicolumn{2}{|c|}{ Regulação do humor prejudicada } \\
\hline Fatores relacionados & Características definidoras \\
\hline $\begin{array}{l}\text { - Abuso de substância; } \\
\text { - Ideias de suicídio recorrente; } \\
\text { - Solidão. }\end{array}$ & $\begin{array}{l}\text { - Afeto triste; } \\
\text { - Culpa excessiva; } \\
\text { - Desesperança. }\end{array}$ \\
\hline \multicolumn{2}{|c|}{ Disposição para enfrentamento melhorado } \\
\hline \multicolumn{2}{|c|}{ Característica definidora } \\
\hline \multicolumn{2}{|c|}{ Expressão do desejo de aumentar o uso de estratégias voltadas ao problema. } \\
\hline \multicolumn{2}{|c|}{ Disposição para resiliência melhorada } \\
\hline \multicolumn{2}{|c|}{ Característica definidora } \\
\hline $\begin{array}{l}\text { ar a própria responsabi } \\
\text { Disposição para }\end{array}$ & $\begin{array}{l}\text { idade pelas ações. } \\
\text { oder melhorado }\end{array}$ \\
\hline
\end{tabular}




\begin{tabular}{|c|}
\hline Característica definidora \\
\hline Expressão do desejo de aumentar a identificação de escolhas possíveis para uma mudança. \\
\hline
\end{tabular}

Fonte: Dados primários do estudo (2020).

No contexto do Domínio 10 (Princípios da vida), foram identificados os títulos diagnósticos de Sofrimento moral (n=12; 6\%); Conflito de decisão (n=6; 3\%); Disposição para tomada de decisão melhorada ( $\mathrm{n}=4 ; 2 \%)$; Sofrimento espiritual (n=2; $1 \%)$. Para o Domínio 11 (Segurança e Proteção), identificaram-se os títulos diagnósticos Risco de infecção (n=16; 8,0\%); Risco de suicídio $(\mathrm{n}=12 ; 6,0 \%)$; Risco de integridade da membrana mucosa oral prejudicada $(\mathrm{n}=5 ; 2,5 \%)$; Automutilação (n=2; $1,0 \%)$; Risco de violência direcionada a outros $(n=2 ; 1,0 \%)$ e Integridade da membrana mucosa oral prejudicada $(n=1 ; 0,5 \%)$, finalmente, o Domínio 12 (Conforto), elencou como DE Isolamento social ( $\mathrm{n}=17 ; 8,5 \%)$ e Risco de solidão ( $\mathrm{n}=7$ / $\mathrm{f}=3,5 \%)$. A caracterização dos Diagnósticos referentes a esse domínio se encontra disposta no Quadro 5 a seguir.

Quadro 5. Caracterização dos Diagnósticos de Enfermagem referentes aos domínios Princípios da vida; Segurança e Proteção; e Conforto identificados no estudo. Caucaia-CE, 2020.

\begin{tabular}{|c|c|}
\hline \multicolumn{2}{|c|}{ DOMÍNIO 10: Princípios da vida } \\
\hline \multicolumn{2}{|c|}{ Sofrimento moral } \\
\hline \multicolumn{2}{|c|}{ Característica definidora: Angústia acerca de agir conforme a escolha moral } \\
\hline \multicolumn{2}{|c|}{ Fatores relacionados } \\
\hline \multicolumn{2}{|c|}{$\begin{array}{l}\text { - Conflito entre os tomadores de decisão; } \\
\text { - Dificuldade de chegar a uma decisão sobre o tratamento. }\end{array}$} \\
\hline \multicolumn{2}{|c|}{ Conflito de decisão } \\
\hline Fator relacionado & Características definidoras \\
\hline Conflito com obrigação moral. & $\begin{array}{l}\text { - Atraso na tomada de decisão; } \\
\text { - Questionamento de valores morais e pessoais ao } \\
\text { tentar chegar a uma decisão. }\end{array}$ \\
\hline \multicolumn{2}{|c|}{ Disposição para tomada de decisão melhorada } \\
\hline \multicolumn{2}{|c|}{ Característica definidora } \\
\hline \multirow{2}{*}{\multicolumn{2}{|c|}{$\begin{array}{c}\text { Expressão do desejo de melhorar a análise de riscos- } \\
\text { Sofrimento espiritual }\end{array}$}} \\
\hline & \\
\hline Fator relacionado & Características definidoras \\
\hline Abuso de substâncias & $\begin{array}{l}\text { - Ansiedade; } \\
\text { - Choro; } \\
\text { - Fadiga; } \\
\text { - Medo; } \\
\text { - Questionamento do sentido da vida; } \\
\text { - Aceitação inadequada; } \\
\text { - Culpa; } \\
\text { - Desesperança. }\end{array}$ \\
\hline
\end{tabular}

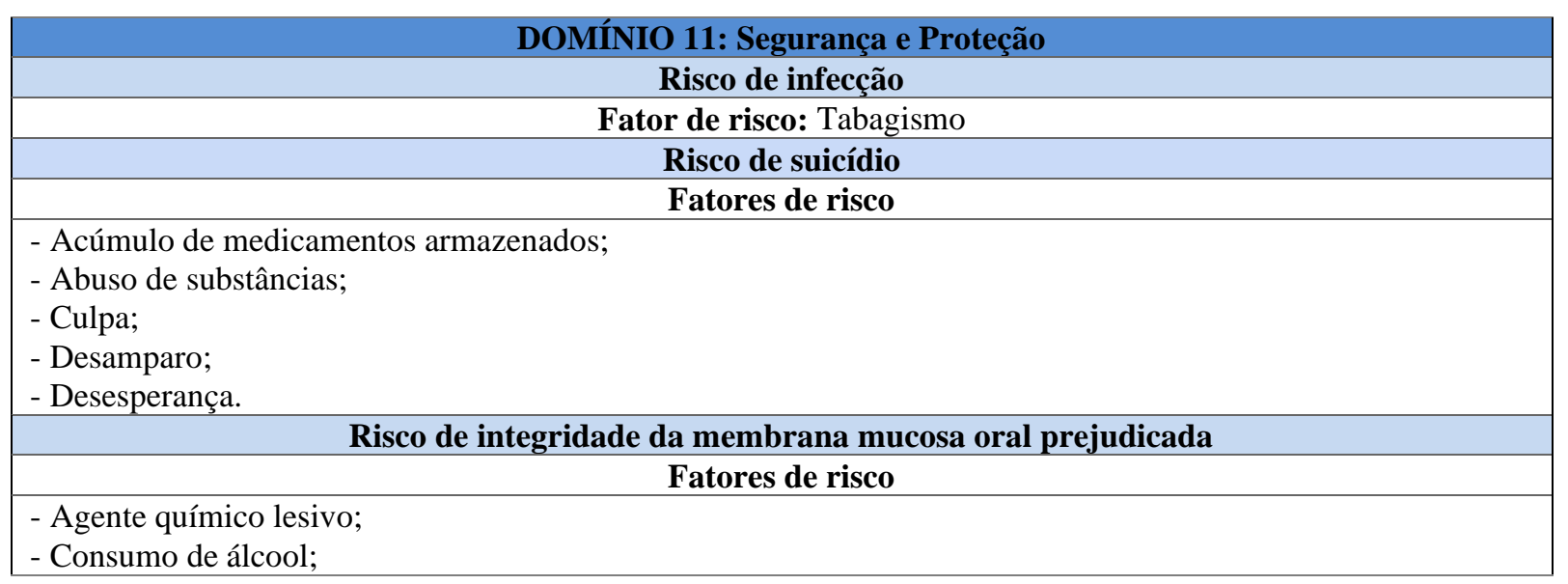




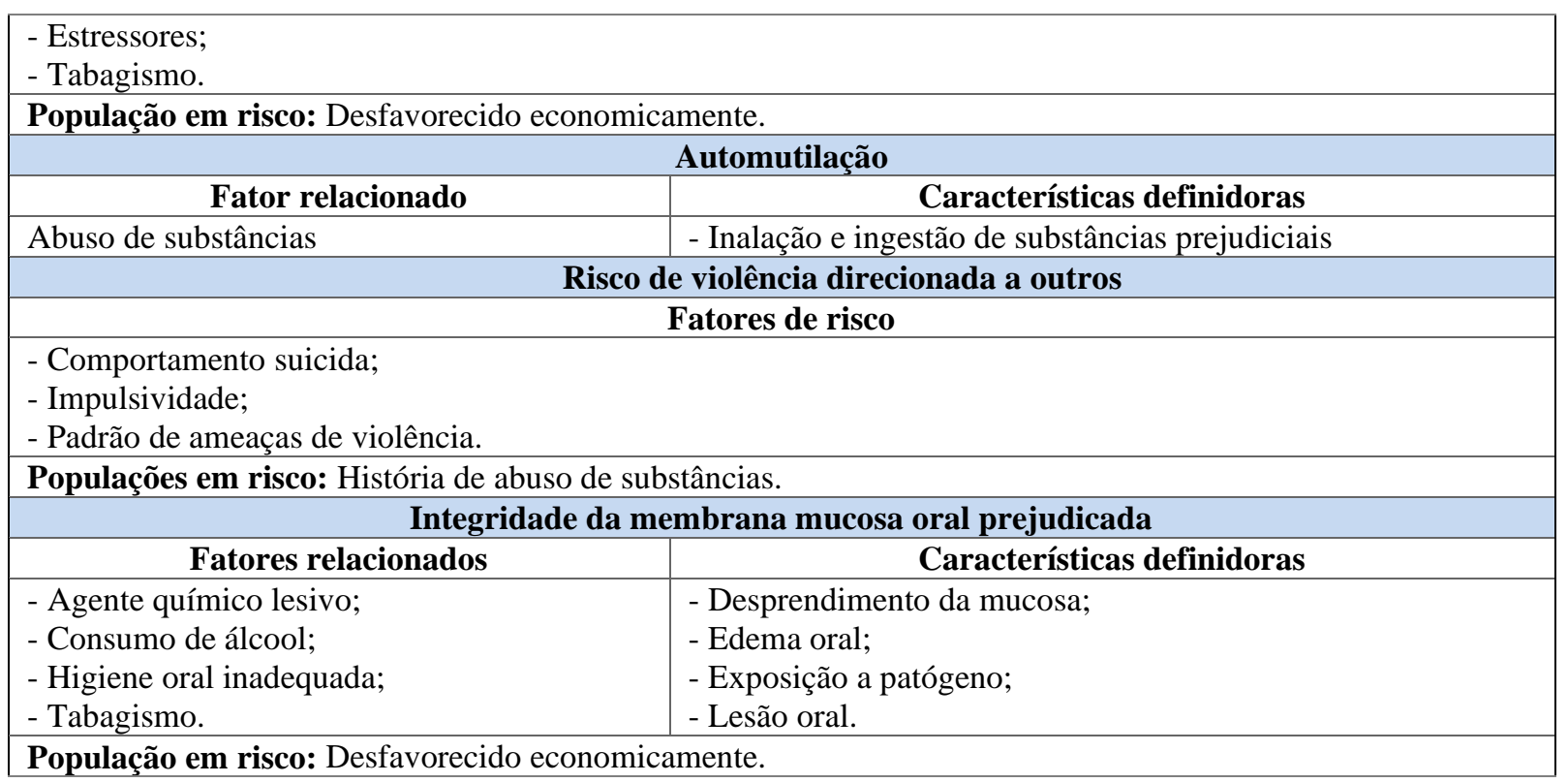

\begin{tabular}{|l|l|}
\hline \multicolumn{2}{|c|}{ DOMÍNIO 12: Conforto } \\
\hline \multicolumn{1}{|c|}{ Isolamento social } \\
\hline \multicolumn{1}{|c|}{ Fatores relacionados } & \multicolumn{1}{c|}{ Características definidoras } \\
\hline $\begin{array}{l}\text { - Comportamento social incoerente com as normas; } \\
\text { - Dificuldade para estabelecer relacionamentos. }\end{array}$ & $\begin{array}{l}\text { - Afeto triste; } \\
\text { - Desejo de estar sozinho; } \\
\text { Risco de solidão }\end{array}$ \\
\hline \multicolumn{1}{|c|}{ Fistória de rejeição. } \\
\hline
\end{tabular}

Fonte: Dados primários do estudo (2020).

\section{Discussão}

Para fins de discussão, apresenta-se a seguir a organização dos DE identificados no estudo por domínio, trazendo seus principais elementos estruturais e contextualizando sua existência na realidade do sofrimento mental decorrente do uso/abuso de álcool e outras drogas. Ressalta-se que a análise do prontuário de cada usuário do CAPS AD permitiu identificar mais de um DE concomitantemente.

\section{Categoria: Diagnósticos de Enfermagem com foco no problema e de risco}

Nesta categoria foram identificados os DE que ressaltavam problemas ou necessidades apresentadas pelos usuários, bem como a vulnerabilidade para desenvolvê-los. Contabilizaram-se 28 títulos diagnósticos que foram divididos em três subcategorias: 1) Problemas de enfrentamento e na autopercepção; 2) Problemas autodirigidos; e 3) Problemas biológicos, físicos, psicológicos e sociais.

É relevante mencionar que a subcategorização dos títulos diagnósticos se procedeu para tornar a discussão dos achados do estudo mais didática, tendo em vista o elevado quantitativo de dados encontrado. No entanto, chama-se a atenção para que a compreensão de tais enunciados seja feita de forma contextualizada uma vez que muitos dos problemas ou riscos encontrados, assim como a expressão, por parte dos usuários, do desejo de melhorar ou modificar contextos desfavoráveis tem fortes interrelações entre si. Ou seja, um risco pode se transformar em um problema e este, por sua vez, desencadear ou favorecer o surgimento de outros, e assim por diante.

A seguir, são descritas as subcategorias temáticas com os títulos diagnósticos de Enfermagem seguidos das respectivas definições. 


\section{1) Problemas de enfrentamento e na autopercepção}

Estão descritos os principais títulos diagnósticos de Enfermagem identificados no contexto do abuso de drogas referentes às questões subjetivas dos usuários, envolvendo os aspectos de suas relações com as substâncias e como elas interferem na percepção destes sujeitos acerca de si e de sua relação com o mundo.

Foram identificados oito títulos e suas respectivas definições: Enfrentamento ineficaz: "Padrão de avaliação inválida de estressores, com esforços cognitivos e/ou comportamentais, que falha em controlar as demandas relativas ao bem estar"; Sentimento de impotência: "Experiência vivida de falta de controle sobre uma situação, inclusive uma percepção de que as próprias ações não afetam, de forma significativa, um resultado"; Resiliência prejudicada: “Capacidade diminuída de se recuperar de situações adversas ou alteradas percebidas, por meio de um processo dinâmico de adaptação"; Conflito de decisão: "Incerteza sobre o curso de ação a ser tomado quando a escolha entre ações conflitantes envolve risco, perda ou desafio a valores e crenças"; Baixa autoestima situacional: "Desenvolvimento de percepção negativa sobre o seu próprio valor em resposta a uma situação atual"; Risco de dignidade humana comprometida: "Suscetibilidade à perda percebida de respeito e honra que pode comprometer a saúde"; Sofrimento moral: "Resposta à incapacidade de pôr em prática as decisões e/ou ações éticas ou morais escolhidas"; Sofrimento espiritual: "Estado de sofrimento relacionado à capacidade prejudicada de experimentar significado na vida por meio de conexões consigo mesmo, com os outros, com o mundo ou com um poder maior".

Analisados em conjunto, os títulos diagnósticos refletem uma acentuada situação de conflito interno dos sujeitos frente à capacidade de lidar com os estressores externos que circundam o contexto de abuso de substâncias. Salienta-se que este envolve uma pluralidade de elementos intra- e interpessoais, físicos, psicobiológicos, sociais e econômicos que afetam os indivíduos de maneira global, podendo levá-los a processos de enfrentamento ineficaz e, além de abusivo, o uso crônico de drogas. O resultado desse processo, geralmente, causa impacto negativo na relação consigo mesmo, com o outro e com o mundo e pode levar a quadros de sofrimento físico, psíquico, moral e espiritual.

Nesse contexto, uma variável importante a ser analisada em relação ao transtorno por uso de substâncias é o estresse. Eventos estressores ao longo da vida do indivíduo podem contribuir para o uso de substâncias, apresentando-se como uma maneira desadaptativa de aliviar tais sintomas (Enoch, 2003). Além disso, altos níveis de eventos estressantes entre usuários de drogas em tratamento e em abstinência podem dificultar o manejo de enfrentamento de suas angústias e aumentar o desejo pela substância, elevando as possibilidades de retorno ao uso (Sinha, 2009). Logo, ressalta-se a importância da diminuição do estresse como um fator de proteção, possibilitando a redução dos desejos de utilizar drogas e o auxílio da promoção da abstinência em usuários que estão em tratamento.

No que tange ao uso e abuso de substâncias, pode-se considerá-lo como um fenômeno multifacetado cujo enfrentamento requer um conjunto articulado de esforços de diferentes esferas (Brasil, 2014). Os estudos têm avaliado as habilidades de enfrentamento em pessoas dependentes de substâncias psicoativas, principalmente com foco no abuso de álcool e crack (Coelho, Sá, \& Oliveira, 2015), e envolvem aspectos socioculturais que consideram principalmente a natureza da droga, ressaltando-se se esta é lícita ou ilícita, refletindo no reforço ao uso ou sua repressão, respectivamente.

Quanto a esse aspecto, destacam-se alguns termos que permeiam o uso e abuso de álcool e outras drogas, principalmente quando se considera a perspectiva de tratamento predominantemente baseada na abstinência e não na redução de danos. Citamse os conceitos de craving (fissura) definido como um desejo ou forte impulso de experimentar ou repetir a experiência dos efeitos de certa substância, com expectativa de resultados positivos, e que envolve avaliação cognitiva e processo cognitivo não automático (Laranjeira et al., 2012; Araújo et al., 2008); lapso, que é uma violação inicial das regras da abstinência, caracterizado como um retorno momentâneo ao hábito, mas sem representar um retrocesso do indivíduo ao padrão anterior à abstinência; e recaída, além do retorno ao consumo da substância, o indivíduo retoma o seu padrão comportamental anterior à abstinência (Kolling, Petry, \& Melo, 2011). 
Em relação aos conceitos supracitados, citam-se alguns estudos que os relacionam à capacidade de enfrentamento dos indivíduos dependentes em situação de abstinência, onde esses indivíduos apresentaram maior repertório de habilidades de enfrentamento imediatas (Dolan et al., 2013; Matto, Chakrabarti, \& Anjaiah, 2009; Souza, 2015). Nas situações de diminuição do consumo, de problemas relacionados e/ou frequência de uso de drogas foram observados resultados semelhantes (Forys, McKellar, \& Moos, 2007; Monti et al., 2005; Donovan, 2009).

Percebe-se que o processo de enfrentamento está intimamente relacionado ao desfecho comportamental dos indivíduos frente ao uso ou abuso das substâncias psicoativas. Desta forma, salienta-se que os títulos diagnósticos Sentimento de impotência, Resiliência prejudicada, Conflito de decisão, Baixa autoestima situacional, Risco de dignidade humana comprometida, Sofrimento moral e Sofrimento espiritual, refletem-se como a via final desse atravessamento do usuário tanto no seu contexto interpessoal, mas, principalmente, no intrapessoal.

Geralmente a busca por substâncias psicoativas ocorre em contextos de fuga ou como forma de enfrentamento de outras situações de vida. Embora, essas substâncias atuem biologicamente nas dimensões humor e ansiedade como diluidora de tensões, o uso recreativo e indiscriminado pode gerar dependência física e psicológica, além do risco de efeitos paradoxais, como depressão e ideação suicida (Smith, Goldsteins, \& Grant, 2016; Eaton et al., 2017). Percebe-se, pois, que a recorrência às substâncias deixa de ser um modo de alívio para se tornar um problema adicional ao contexto de vida do indivíduo.

\section{2) Problemas autodirigidos}

Esta subcategoria elenca quatro títulos diagnósticos com suas respectivas definições, e aponta para posturas/ações realizadas pelos sujeitos no contexto de sua própria vontade quanto aos aspectos de autocuidado e autopreservação relacionados ao uso e abuso de substâncias psicoativas: Comportamento de saúde propenso a risco: "Capacidade prejudicada de modificar o estilo de vida e/ou as ações de forma a melhorar o nível de bem-estar"; Autonegligência: "Conjunto de comportamentos culturalmente estruturados que envolvem uma ou mais atividades de autocuidado em que há falha em manter um padrão de saúde e bem-estar socialmente aceito"; Risco de suicídio: "Suscetibilidade à lesão autoinfligida que ameaça a vida"; e Automutilação: "Comportamento autolesivo deliberado, causando dano tissular, com a intenção de provocar lesão não fatal para obter alívio de tensão".

Ressalta-se que tais títulos diagnósticos apresentaram como fatores de risco, fatores relacionados ou características definidoras o "abuso de substâncias". Desta forma, devese considerar todo o contexto que abrange o uso/abuso de álcool e outras drogas, compreendendo as interrelações entre a subjetividade dos usuários e o meio social que o cerca, representado pelas interações interpessoais e sua rede de apoio disponível e percebida.

O título Comportamento de saúde propenso a risco foi identificado entre pessoas em sofrimento psíquico decorrente de transtornos mentais (Brusamarello et al., 2013; Cardoso \& Galera, 2009) e do abuso de substâncias (Teixeira et al., 2015; Cantão \& Botti, 2016). Nos estudos, o problema foi resultado principalmente da não adesão ao tratamento, seja farmacológico ou não farmacológico, representado pelo absenteísmo às consultas agendadas e às atividades propostas no Projeto Terapêutico Singular. Como consequência, compreende-se que esses comportamentos podem levar a um agravamento do sofrimento, além de dificultar a reintegração social do paciente, refletindo no elevado risco para reinternações.

Quanto ao título diagnóstico risco de suicídio, considerando-se que o estudo apontou o álcool como droga de preferência dos usuários ( $\mathrm{n}=77 ; 38,5 \%$ ), além de estar associado ao uso de múltiplas substâncias ( $\mathrm{n}=56 ; 28 \%$ ), salienta-se que está associado a aumento significativo no risco de acidentes, violência e suicídio. $\mathrm{O}$ uso problemático e grave da substância também contribui para desinibição e sentimento de tristeza e irritabilidade, os quais colaboram para tentativas de suicídio e suicídios consumados (DSM-V, 2014).

O comportamento suicida é um problema multifacetado, onde a presença de transtornos mentais aumenta a sua 
vulnerabilidade (Arribas-Ibar et al., 2017). Mais de 90\% das pessoas com este tipo de comportamento têm transtorno mental crônico diagnosticável, sendo mais comuns a depressão, a esquizofrenia e o abuso de substâncias.

Já foi observado que uso de substâncias é um importante fator de risco associado à ideação e/ou tentativa de suicídio (Lima et al., 2010; Pompili et al., 2010; Cantão \& Botti, 2016). Apesar de o risco existir entre homens (Ribeiro, 2012) e mulheres (Da Silveira et al., 2014; Dragisic et al., 2015), entre estas é considerado mais problemático tendo em vista que o contexto do consumo de drogas vem associado à promiscuidade, à imoralidade, expõe-nas a situações de violência e favorece o surgimento de comorbidades psiquiátricas, tais como Depressão, Transtorno Bipolar, Transtorno de Personalidade, dentre outros (OlivanBlazquez et al., 2016) que, por sua vez, converge para o comportamento suicida (Felix et al., 2016; Machado \& Santos, 2015).

Quanto ao DE automutilação, conforme mostram os estudos, caracteriza-se como um comportamento que ocorre em diversas faixas etárias, mas é predominante em adolescentes, principalmente do sexo feminino (Cedaro \& Nascimento, 2013). Em geral, tem início entre os 13 e 14 anos e pode persistir por 10 ou 15 anos ou ainda, por mais tempo (Giusti, 2013). Levandose em consideração que o uso de substâncias psicoativas geralmente acontece nesta fase do ciclo vital e que o comportamento para automutilação pode ser ratificado por outros fatores como transtornos mentais, falta de escolaridade e de formação profissional e/ou emprego, reforça-se que os adolescentes são grupo de alto risco para a prática (Mars et al., 2014).

\section{3) Problemas biológicos, físicos, psicológicos e sociais}

Quanto aos problemas biológicos, nesta subcategoria foram identificados quatro títulos diagnósticos relacionados à deficiência de duas necessidades humanas básicas, Nutrição desequilibrada: menor do que as necessidades corporais e Insônia, respectivamente definidas como "Ingestão de nutrientes insuficiente para satisfazer às necessidades metabólicas" e "Distúrbio na quantidade e qualidade do sono que prejudica o desempenho normal das funções da vida diária", além dos riscos de adoecimento por meio dos títulos Risco de função hepática prejudicada, definido como "Suscetibilidade à diminuição na função hepática que pode comprometer a saúde" e Risco de infecção, definido como: "Suscetibilidade à invasão e multiplicação de organismos patogênicos que pode comprometer a saúde".

Já em relação aos problemas físicos, foram identificados dois títulos diagnósticos para a mesma situação: Integridade da membrana mucosa oral prejudicada, definida como "Lesão em lábios, tecidos moles, cavidade oral e/ou orofaringe" ou Risco para Integridade da membrana mucosa oral prejudicada, evidenciando a suscetibilidade para tal. Apesar do contexto de vulnerabilidade dos usuários abranger outros fatores de risco e relacionados, como agente químico lesivo, higiene oral inadequada, tabagismo e estressores, salienta-se que o consumo ou abuso de álcool foi identificado na quase totalidade dos títulos diagnósticos como fator principal para os problemas.

Apesar da escassez de estudos no Brasil, tem-se evidenciado que a dependência de álcool e outras drogas influencia de modo significativo a situação alimentar e nutricional dos usuários, seja no aspecto biológico, por afetar o apetite, a ingestão adequada de nutrientes e o estado nutricional, seja no que concerne ao componente social, impactando nos hábitos alimentares, no autocuidado e na escolha adequada de alimentos (Neale et al., 2012). Tanto a desnutrição (Tang et al., 2011; Chaves et al., 2011) quanto a obesidade (Ribeiro \& Siqueira, 2016), assim como episódios de compulsão alimentar (Heber \& Carpenter, 2011) têm sido relatados entre usuários de drogas ou em processo de tratamento para dependência. Os alimentos escolhidos por essa população são geralmente os de baixos teor nutricional e custo, de fácil preparo e de consumo rápido (Saeland et al., 2011; Ferreira et al., 2015).

Quanto ao uso do álcool, a literatura tem revelado relações complexas entre a ingestão desta substância, principalmente de modo excessivo e crônico, a déficits no estado nutricional. Isso se dá devido às alterações hepatocelulares na absorção de nutrientes e pela própria diminuição da ingestão de alimentos (Otero \& Cortés, 2008); além disso, destaca-se o risco de danos estruturais ao parênquima hepático e desenvolvimento de condições mais graves como a cirrose (Mincis \& Mincis, 2011). 
Outro achado relevante relacionado à ingestão alimentar insuficiente está intimamente relacionado à Integridade da membrana mucosa oral prejudicada. Isso se torna mais crítico no contexto do uso do crack, uma vez que a alimentação pode ser prejudicada pelas lesões na região orofaríngea causadas pelo uso de cachimbos produzidos com latas de alumínio. O contato repetido com alumínio aquecido provoca o surgimento de bolhas e feridas na língua, nos lábios, rosto e também nos dedos (Oliveira \& Napo, 2008).

Nesse contexto, o risco para infecção se torna acentuado devido à multiplicidade de fatores desfavoráveis à manutenção de um organismo saudável. Além do comprometimento dos padrões de sono e alimentar, bem como a autonegligência, outros fatores que envolvem o uso de substâncias psicoativas, como compartilhamemnto de seringas, multiplicidade de parceiros e relações sexuais desprotegidas, podem aumentar a vulnerabilidade individual e comunitária para infecções como o HIV, hepatites, tuberculose e outras infecções sexualmente transmissíveis (IST) (Luo et al., 2012; Li, Li, \& Stanto, 2010; Ti et al., 2011; Debeck et al., 2011; Santos, 2014).

Finalmente, no que concerne aos problemas psicológicos, foram identificados como principais títulos diagnósticos respectivamente definidos: Síndrome de abstinência de substâncias aguda: "Sequelas graves e multifatoriais após cessação repentina de uma substância aditiva"; Ansiedade: "Sentimento vago e incômodo de desconforto ou temor, acompanhado por resposta autonômica (a fonte é frequentemente não específica ou desconhecida para o indivíduo); sentimento de apreensão causado pela antecipação de perigo. É um sinal de alerta que chama a atenção para um perigo iminente e permite ao indivíduo tomar medidas para lidar com a ameaça"; Regulação do humor prejudicada: "Estado mental caracterizado por mudanças no humor ou no afeto e que abarca uma série de manifestações afetivas, cognitivas, somáticas e/ou fisiológicas, variando de leves a graves"; Controle emocional lábil: "Rompantes incontroláveis de expressão emocional exagerada e involuntária”; e Confusão aguda: "Distúrbios reversíveis de consciência, atenção, cognição e percepção que surgem em um período de tempo breve, com duração inferior a 3 meses".

Segundo o DSM-V (2014), os transtornos relacionados a substâncias dividem-se em dois grupos: transtornos por uso de substância e transtornos induzidos por substância. As condições a seguir podem ser classificadas como induzidas por substância: intoxicação, abstinência (no contexto da Enfermagem o título diagnóstico Síndrome de abstinência de substâncias aguda) e outros transtornos mentais induzidos por substância/medicamento, citando-se: transtornos psicóticos; transtorno do humor - depressivos, bipolar e transtornos relacionados (no contexto da Enfermagem os títulos diagnósticos Regulação do humor prejudicada e Controle emocional lábil); transtornos de ansiedade (no contexto da Enfermagem o título diagnóstico Ansiedade); transtorno obsessivo-compulsivo e transtornos relacionados; transtornos do sono; disfunções sexuais, delirium (no contexto da Enfermagem o título diagnóstico Confusão aguda) e transtornos neurocognitivos.

Já foram anteriormente salientadas as consequências individuais que o uso de drogas envolve, considerando maior vulnerabilidade a doenças físicas, prejuízos nas relações familiares, sociais e profissionais, além de maior incidência de psicopatologias (Diehl, Cordeiro, \& Laranjeira, 2011; Fox, Oliver, \& Ellis, 2013). Neste contexto, oportunamente, destacam-se mais cinco títulos diagnósticos decorrentes das disfuncionalidades interpessoais provocadas pelo uso de substâncias: Processos familiares disfuncionais: "funcionamento familiar que falha em sustentar o bem-estar de seus membros; Desempenho de papel ineficaz: "padrão de comportamento e autoexpressão que não combina com o contexto, as normas e as expectativas do ambiente"; Risco de violência direcionada a outros: "Suscetibilidade a comportamentos nos quais um indivíduo demonstra que pode ser física, emocional e/ou sexualmente nocivo a outros"; Isolamento social: "Solidão sentida pelo indivíduo e percebida como imposta por outros e como um estado negativo ou ameaçador"; Risco de solidão: "Suscetibilidade a desconforto associado ao desejo ou necessidade de ter mais contato com os outros que pode comprometer a saúde".

Diversos estudos discutem o alto índice de comorbidades psiquiátricas em indivíduos que usam substâncias, destacandose os transtornos depressivos e de ansiedade (Andretta et al., 2018; Hess, Almeida, \& Moraes, 2012; Scheffer, Passa, \& Almeida, 
2010; Staiger et al., 2011; Boschloo et al., 2012).

Pacientes em tratamento para transtorno por uso de substâncias com sintomas depressivos, possuem menor qualidade de vida (Marcon et al., 2014) e maiores índices de retorno ao uso da droga em comparação a pacientes que não possuem tal sintomatologia (Saatcioglu, Yapici, \& Cakmak, 2008). Isso pode estar relacionado aos achados de nosso estudo, principalmente os que dizem respeito às relações interpessoais, como o risco de solidão e isolamento social, os quais podem contribuir para o desenvolvimento de alterações do humor, especialmente a depressão.

Nessa perspectiva, justifica-se o fato de que sintomatologia depressiva implica em uma maior probabilidade de internação hospitalar para tratamento decorrente do uso de drogas e no aumento da busca de tratamento ambulatorial por essa população (Argimon et al., 2013). Logo, é de suma importância que os sinais e sintomas da doença sejam identificados precocemente e manejados de forma e evitar desfechos mais graves como tentativa de suicídio. $\mathrm{O}$ acompanhamento dos pacientes por uma equipe multiprofissional tanto na APS quanto nos serviços especializados, deve ser cuidadosamente planejado.

No que tange aos títulos Processos familiares disfuncionais e Desempenho de papel ineficaz, aponta-se que embora o abuso de drogas ocorra em um corpo individual, esta produz impactos que incidem não apenas sobre o usuário, mas as suas famílias e a comunidade. Logo, vivenciar por um tempo prolongado à dependência de drogas faz com que as pessoas que integram o grupo familiar sejam afetadas em inúmeras dimensões, tais como: psicológicas, afetiva, financeira e social; abalando as relações intrafamiliares. Não obstante, os encargos conferidos por um ambiente permeado pelas drogas geram a exclusão social e o estigma, que podem contribuir para a sobrecarga e o adoecimento do grupo (Reis, Sales, \& Oliveira, 2017; Rodrigues et al., 2018); estremece a autoestima da família, suscitando sentimentos de decepção, desconfiança, desacreditação, impotência e angústia, que ao serem experimentados rotineiramente, desmotivam as pessoas a continuar investindo esforços no cuidado com o outro (Andrade et al., 2016).

\section{Categoria - Diagnósticos de Promoção da Saúde}

Nesta divisão, foram visualizados os DE que enfatizam a promoção da saúde. Foram identificados nove títulos diagnósticos, os quais estão inseridos nos seguintes domínios: Promoção da saúde, atividade/repouso, percepção/cognição, papéis e relacionamentos e enfrentamento e tolerância ao estresse.

Segundo a definição da NANDA-I (2018-2020, p. 48), define-se como diagnóstico de promoção da saúde:

Julgamento clínico a respeito da motivação e do desejo de aumentar o bem-estar e alcançar o potencial humano de saúde. Essas respostas são expressas por uma disposição para melhorar comportamentos de saúde específicos, podendo ser usadas em qualquer estado de saúde. [...] podem existir em um indivíduo, família, grupo ou comunidade.

Buss (2000) discorre que promoção da saúde, nas últimas duas décadas, configura como método propício para combater os diversos problemas de saúde que afetam as populações humanas e seus entornos neste final de século. A partir de uma visão ampliada do processo saúde-doença e de suas causas, preconiza o entendimento entre saberes técnicos e populares, e a associação de instrumentos institucionais e comunitários, públicos e privados, para seu combate e solução.

Promoção da saúde é a designação dada ao método de qualificação da comunidade para empreender melhoria de sua qualidade de vida e saúde, incluindo uma maior atuação na administração desse recurso. Buscando um estado de completo bem estar físico, mental e social os sujeitos e coletivos carecem discernir interesses, corresponder necessidades e metamorfosear favoravelmente o meio ambiente. Logo, a promoção da saúde não é incumbência restrita ao setor saúde, e vai para além de um estilo de vida saudável, no rumo de um bem-estar global.

No que concerne à categoria Diagnósticos de Promoção da saúde descrevem-se os principais títulos diagnósticos de Enfermagem identificados no contexto do uso/abuso de substâncias psicoativas evidenciados para a melhora qualidade de vida, 
bem com desejo de melhora. Discorre sobre o que ocorre a partir do prisma destes usuários em relação a si, assim como suas relações de enfrentamento e melhora e aperfeiçoamento das relações como um todo. Vale ressaltar que estes diagnósticos possuem estreita correspondência, ocorrendo em sua integralidade de acordo com as possibilidades de cuidados ofertados.

Os oito títulos diagnósticos constatados no domínio de promoção da saúde estão listados a seguir com suas respectivas definições: Disposição para melhora do autocuidado: "Padrão de realização de atividades para si mesmo para atingir as metas relativas à saúde que pode ser melhorado". Disposição para controle da saúde melhorado: "Expressão do desejo de melhorar: 1) as escolhas da vida diária para alcançar metas; 2) o controle de fatores de risco e; 3) o controle de regimes prescritos" Disposição para conhecimento melhorado: "Padrão de informações cognitivas ou de aquisição de informações relativas a um tópico específico, que pode ser melhorado". Disposição para processos familiares melhorados: "padrão de funcionamento familiar para sustentar o bem-estar de seus membros que pode ser melhorado". Disposição para enfrentamento melhorado: "Padrão de avaliação válida de estressores, com esforços cognitivos e/ou comportamentais, para controlar as demandas relativas ao bemestar, que pode ser melhorado. Disposição para resiliência melhorada: "Padrão de capacidade de se recuperar de situações adversas ou alteradas percebidas, por meio de um processo dinâmico de adaptação, que pode ser melhorado”. Disposição para poder melhorado: "Padrão de participação intencional na mudança para o bem-estar que pode ser melhorado". Disposição para tomada de decisão melhorada: "Padrão de escolha de um curso de ação para atingir metas de saúde de curto e longo prazos que pode ser melhorado".

Quando verificado o agrupamento dos títulos diagnósticos de fomento à saúde, no viés de discussão, torna-se perceptível que são análogos e convergem para um perfil de restabelecimento de alguma dimensão da vida do cliente. Vale ressaltar que esses diagnósticos estão embasados na perspectiva de disposição para a melhora do estado de saúde ou processo de vida; a condição entusiasta, dentro de um plano terapêutico, deve ser animada no intuito de possibilitar o manejo dos sofrimentos físico, psíquico, moral e espiritual. Além disso, firmam estrutura para que se desenvolvam processos de enfrentamento eficaz.

No tocante à prática da Enfermagem, os processos de educação e saúde, bem como as consultas individuais, podem auxiliar nesse processo desse enfrentamento. A assistência de Enfermagem ocorre a partir do acolhimento, perpassando a escuta qualificada, com foco na individualidade do sujeito e na maneira como interage com os meios sociais. Faz-se necessário entender como lidar com o uso de substâncias psicoativas a partir da realidade do sujeito, estruturando medidas de cuidados de forma conjunta, para que venham a ser resolutivas no ponto de vista biopsicossocial.

Os diagnósticos de disposição para melhora do autocuidado, disposição para controle da saúde melhorado e disposição para conhecimento melhorado confluem entre si no que tange ao restabelecimento das práticas de saúde. De acordo com Orem (2001), o autocuidado é definido como o exercício de atividades pelo indivíduo para sua melhoria, intentando a manutenção da vida, da saúde e do bem-estar. Logo, torna-se exequível a implementação e fortalecimento do conhecimento da própria situação de salubridade, atividade essa que decorre a partir da realização de consultas individuais e compartilhadas, realização de grupos terapêuticos, bem como acompanhamento pelos profissionais e familiares no contexto dos diversos recursos terapêuticos que alicerçam as assistências, fornecendo eixos de cuidados no manejo do empoderamento e desenvolvimento de estratégias para o autocuidado.

Em relação aos diagnósticos de disposição para processos familiares melhorados, disposição para enfrentamento melhorado e disposição para resiliência melhorada constata-se que trazem enquanto conformidade o propósito para melhoria de métodos nas relações familiares e nas relação intrapessoal. No que diz respeito a essa sincronicidade, implicam em aspectos de melhora do enfrentamento, da resiliência, do poder melhorado e melhor tomada de decisão por parte do usuário. Conforme Silva et al. (2005) a concepção de resiliência concerne a possibilidade dos seres humanos em confrontar e responder de modo positivo às experiências que possuem elevada capacidade de risco para sua saúde e desenvolvimento. Já a definição de enfrentamento traz que é o ato ou efeito de enfrentar; disputa em torno de questões polêmicas; contestação, controvérsia, debate (Enfrentamento, 
2020).

A política do Ministério da Saúde para o enfrentamento às drogas enfoca a prevenção e redução de danos (De Micheli et al., 2004). Nesse contexto, ressalta-se a utilização de uma estratégia de ricas possibilidades que é a realização de grupos. Consoante com Bastos (2010), aprender em grupo significa uma leitura crítica da realidade, uma atitude investigadora, uma abertura para as dúvidas e para as novas inquietações. Portanto, a aprendizagem é um processo contínuo em que comunicação e interação são indissociáveis, na medida em que aprendemos a partir da relação com os outros. A aprendizagem centrada nos processos grupais coloca em evidência a possibilidade de uma nova elaboração de conhecimento, de integração e de questionamentos acerca de si e dos outros.

Dentre as diversas modalidades de abordagem grupal, destaca-se o grupo operativo, que teve sua técnica sistematizada pelo médico psiquiatra Enrique Pichon-Rivière, como uma estratégia importante no sentido de favorecer a melhoria na qualidade da assistência ao paciente e seus familiares. Através do grupo é possível desenvolver uma assistência de saúde geradora de informação, educação em saúde, reflexão e suporte, pois permite ao profissional enfermeiro, reconhecer e compreender a crise motivadora da procura de ajuda (Bourguignon, Guimarães, \& Siqueira, 2010; Mazzuchello, 2014).

Embasado nessa importante ferramenta de cuidados, salienta-se como experiência a realização do grupo de Redução de Danos no CAPS AD no município de Caucaia-CE, o qual surge em 2003 alicerçado na dialética de grupos operativos de PichonRivière, onde foram inseridas equipes multiprofissionais e residentes no intuito de edificar estratégias e habilidades de enfrentamento, tanto para os clientes, como para familiares. Junta-se a realização de grupo terapêutico para família, grupo de enfrentamento ao tabagismo, bem como consultas individuais e compartilhadas na intenção de empoderamento dos sujeitos.

O grupo de redução de danos ocorre uma vez por semana, onde existem duas figuras orientadoras: um condutor e um relator. O condutor explica sobre as regras do grupo que tratam do sigilo, respeito, participação integral no encontro e aprendizagem centrada nos processos grupais. O relator expõe, ao final, todo desenvolvimento do grupo para que haja o fechamento e empoderamento das práticas discutidas. O processo favorece a transformação de si através da leitura da própria realidade e do seu semelhante, prática que estimula a interação, reciprocidade e desenvolvimento de estratégias que predispõemse nas práticas de promoção da saúde, seja no âmbito da abstinência, do uso controlado ou articulação de planos para a redução de danos. A partilha das experiências do cotidiano geram empatia e reconhecimento, bem como permitem aprendizagem de estratégias, para que se conheçam os fatores determinantes de saúde em todos os prismas, o que implica diretamente nos processos de saúde e adoecimento dos mesmos.

A partir desse conhecimento emancipatório, verifica-se a disponibilidade nos processos de melhora e na disposição para tal. No tocante ao respeito das individualidades, cada cliente tem a possibilidade de buscar pelo tratamento ao qual se adequa. De acordo com o princípio da redução de danos, as interposições podem envolver a abstinência, a diminuição do uso da droga ou até mesmo a troca por substâncias que provoquem menos prejuízos à saúde (Vinadé, 2009). O que torna o processo potente é a possibilidade de escolha para melhoria e consequente abertura para os processos familiares melhorados, constituindo uma rede de apoio que, por sua, vez resulta em diminuição de danos e propensão às recaídas.

Diante dos diagnósticos de "disposição para poder melhorado" e "disposição para tomada de decisão melhorada" é notória uma convergência para melhora intencional do curso de saúde. De acordo com a definição da NANDA (2018), o poder melhorado está relacionado diretamente com a participação proposital na mudança para o bem-estar que pode ser melhorado; tal percepção é visualizada a partir da adesão e continuidade dos planos terapêuticos singulares, edificados nas múltiplas estratégias já exemplificadas, acompanhadas sempre pelo desejo de escolha individual de cada usuário do equipamento. Tal anseio age como força motriz dos processos, seja na vivência de melhora, nos processos de abstinência ou nos de recaídas.

De acordo com Cruz, Vargens, e Ramôa (2011), no lugar dos modelos soberanos de tratamento de cunho moral e legal, condutas psicossociais valorizam a oferta de espaços de escuta e acolhimento para o fenômeno das drogas. Nesta direção, 
viabilizar atendimentos em espaços públicos para pessoas que usam drogas, sem ditar abstinência e nem permanência no serviço, é um grande obstáculo e representa uma importante ferramenta no tratamento.

É necessário estimular a prática de rotinas de cuidado que alicercem a expansão de habilidades e potencialidades, ampliando práticas de promoção da saúde, alimentando as disposições para autonomia e o autocuidado, aumentando fatores de proteções individuais, melhorando a resiliência, empoderando as tomadas de decisões nos enfrentamentos de situações de risco. Bem como, estruturar elos de assistência que permitam a inserção comunitária e familiar.

\section{Conclusão}

O presente estudo permitiu identificar os principais Diagnósticos de Enfermagem entre os usuários do CAPS AD do Município de Caucaia-CE, o qual mostrou um perfil de clientela majoritariamente masculina, de adultos jovens, solteiros, com ensino fundamental incompleto, desempenhando algum tipo de ocupação (formal ou informal), que consumiam preferencialmente o álcool, trataram-se anteriormente em comunidades terapêuticas ou no CAPS e apresentavam conflitos familiares e sociais relacionadas ao uso/abuso de substâncias psicoativas.

Segundo a análise dos prontuários, foi possível identificar 37 diagnósticos de Enfermagem com predominância dos com foco no problema, que ressaltavam necessidades apresentadas pelos usuários, bem como a vulnerabilidade para desenvolvê-los, seguido dos de promoção da saúde, sobre motivação e desejo de aumentar o bem-estar com respostas expressas por uma disposição para melhorar comportamentos específicos de saúde.

Com relação à análise dos diagnósticos de risco e com foco no problema, emergiram três subcategorias: 1) Problemas de enfrentamento e na autopercepção; 2) Problemas autodirigidos; e 3) Problemas biológicos, físicos, psicológicos e sociais, nas quais o abuso de substância desponta como elemento relacionado ou de risco para grande parte desses enunciados. Além disso, conforme o perfil dos prontuários analisados, observou-se que o elevado abuso de álcool evidencia a problemática acerca dessa substância em particular, como todo o ônus acarretado não só ao âmbito biológico, mas também da coletividade, por conta dos acidentes de trânsito.

Ao identificar os principais diagnósticos de Enfermagem, foi possível estabelecer um nexo entre os diagnósticos com foco no problema e de risco com os diagnósticos de promoção da saúde, ou seja, confirmou-se a Ciência Enfermagem na resolução de problemas, com organização potencial e capaz de promover a qualidade do cuidado ofertado na Rede de Atenção Psicossocial. Nesse sentido, ressalta-se a necessidade de implantação da Consulta de Enfermagem na RAPS, para que a Sistematização da Assistência de Enfermagem se concretize neste âmbito de cuidados.

Para tanto, faz-se necessário ter condições favoráveis ao desenvolvimento do trabalho da Enfermagem, pois só desta forma haverá alicerce sólido para acompanhar os determinantes sociais de saúde de cunho territorial, bem como ensejo propício para costurar a linearidade nos Diagnósticos de Enfermagem entendendo os indivíduos em suas unicidades, como sujeitos portadores de histórias singulares, que são atravessados por vivências ímpares em suas trajetórias. Tal primordialidade deve ser ponto de apoio para toda e qualquer sugestão de intervenção de Enfermagem delineada no plano de cuidados.

Diante desses achados, sugere-se a realização de novos estudos envolvendo a identificação de Diagnósticos de Enfermagem em outros cenários de cuidados à Saúde Mental, uma vez que tais elementos são primordiais para o desenvolvimento de um plano de cuidados individualizado e que permitirá, junto a outras estratégias da equipe multidisciplinar, prestar um cuidado baseado no verdadeiro princípio da integralidade.

\section{Agradecimentos}

Programa Nacional de Bolsas para Residência Multiprofissional em Saúde do Ministério da Saúde e Escola de Saúde Pública do Ceará. 


\section{Referências}

Almeida, A. J. F., Moraes, A. E. C., \& Peres, M. A. A. (2009). Atuação do enfermeiro nos centros de atenção psicossocialimplicações históricas da enfermagem psiquiátrica. Revista RENE, 10(2), 158-165.

American Psychiatric Association. Manual Diagnóstico e Estatístico de Transtornos MentaisDSM-5. (2014). Porto AlegreArtmed. http://www.niip.com.br/wpcontent/uploads/2018/06/Manual-Diagnosico-e-Estatistico-de-Transtornos-Mentais-DSM-5-1-pdf.pdf>

Andrade, A. C. S., Cardoso, B. D., Souza, J. E. A. P., Campos, M. C., Lima, G. Z., \& Buriola, A. A. (2016). Feelings of relatives of patients hospitalized in the psychiatric emergency care unita look on the Family. Ciência, Cuidado \& Saúde, 15(2), 268-274. http://www.periodicos.uem.br/ojs/index.php/CiencCuidSaude/article/view/25964/17402.

Andretta, I., Limberger, J., Schneider, J. A., \& Mello, L. T. N. de. (2018). Sintomas de Depressão, Ansiedade e Estresse em Usuários de Drogas em Tratamento em Comunidades Terapêuticas. Psico-USF, 23(2), 361-373. : https://dx.doi.org/10.1590/1413-82712018230214

Araujo, R. B., Oliveira, M. S., Pedroso, R. S., Miguel, A. C., \& Castro, M. G. T. de. (2008). Craving e dependência químicaconceito, avaliação e tratamento. Jornal Brasileiro de Psiquiatria, 57(1), 57-63. https://doi.org/10.1590/S0047-20852008000100011

Argimon, I. I., Terroso, L. B.; Farina, M.; Moraes, A. A.; Lopes, R. M. F.; \& Queroti, K. L. M. (2013). A intensidade da depressão e a internação de alcoolistas. Aletheia, 40, 102-110. http://pepsic.bvsalud.org/pdf/aletheia/n40/n40a09.pdf

Arribas-Ibar, E, Suelves, J. M., Sanches-Niubó, A., Domingo-Salvany, A., \& Brugal, M. T. (2017). Suicidal behaviours in male and female users of illicit drugs recruited in drug treatment facilities. Gaceta Sanitaria, 31(4), 292-298.

Bastos, A. B. B. I. (2010). A técnica de grupos-operativos à luz de Pichon-Rivière e Henri Wallon. Psicologo informacao, 14(14), 160-169. http://pepsic.bvsalud.org/scielo.php?script=sci_arttext\&pid=S1415-88092010000100010\&lng=pt\&tlng=pt

Berlinck, M. T., Magtaz, A, C., \& Teixeira, M. (2008). A Reforma Psiquiátrica Brasileiraperspectivas e problemas. Revista Latinoamericana de Psicopatologia Fundamental, 11(1), 21-28. https://doi.org/10.1590/S1415-47142008000100003

Boschloo, L., Vogelzangs, N., Smit, J. H., Van Den Brink, W., Veltmna, D. J., Beekman, A. T.; \& Penninx, B. W. (2011). Comorbidity and risk indicators for alcohol use disorders among persons with anxiety and/or depressive disordersFindings from the Netherlands Study of Depression and Anxiety (NESDA). Journal of Affective Disorders, 131(1), 233-242.

Bourguignon,, L. N., Guimarães, E. D. S., \& Siqueira, M. M. D. (2010). A Atuação do Enfermeiro nos Grupos Terapêuticos dos CAPS AD do Estado do Espírito Santo. Cogitare Enfermagem, 15(3), 467-473.

Brasil. Ministério Público do Distrito Federal e Territórios - MPDFT. (2014). Boas Práticas no Enfrentamento ao Tráfico e Uso de Drogas Ilícitas. BrasíliaMPDFT.

Brusamarello, T., Capistrano, F. C., Oliveira, V. C. de, Mercês, N. N. A. das, \& Maftum, M. A. (2013). Cuidado a pessoas com transtorno mental e familiaresDiagnósticos e intervenções a partir da consulta de enfermagem. Cogitare Enfermagem, 18(2), 245-252. https://revistas.ufpr.br/cogitare/article/view/32574/20686

Buss, P. M. Promoção da saúde e qualidade de vida. (2000). Ciência Saúde Coletiva, 5(1), 163-177. http://www.scielo.br/scielo.php?script=sci_arttext\&pid=S1413-81232000000100014\&lng=en\&nrm=iso

Cantão, L., Botti, N. C. L. (2016). Suicidal behavior among drug addicts. Revista Brasileira de Enfermagem, 69(2), 366-73. https://www.scielo.br/scielo.php?pid=S0034-71672016000200389\&script=sci_arttext\&tlng=en

Cardoso, L., \& Galera, S. A. F. (2009) Doentes mentais e seu perfil de adesão ao tratamento psicofarmacológico. Revista Escola de Enfermagem da USP, $43(1), 161-7$.

Cedaro, J. J., \& Nascimento, J. P. G. (2013). Dor e gozoRelatos de mulheres jovens sobre automutilações. Psicologia USP, $24(2), 203-223$.

Chaves, T. V., Sanchez, Z. M., Ribeiro, L. A., \& Nappo, S. A. (2011). Fissura por crackcomportamentos e estratégias de controle de usuários e ex-usuários. Revista de Saúde Pública, 45(6), 1168-1175.

Coelho, L. R. M., de Sá, L. G. C., \& Oliveira, M. S. (2015). Strategies and coping skills of crack users in treatment. Revista de Psicologia da IMED, 7(2), 99109. https://doi.org/10.18256/2175-5027/psico-imed.v7n2p99-109.

Cossa, R. M. V., \& Almeida, M. A. (2012). Facilidades no ensino do Processo de Enfermagem na perspectiva de docentes e enfermeiros. Revista Rene, 13(3), 494-503. http://dx.doi.org/10.15253/rev\%20rene.v13i3.3965

Cruz, M. S., Vargens, R. W., \& Ramôa, M. L. (2011). Crack, uma abordagem multidisciplinar. InSENAD. Prevenção ao uso indevido de drogas. Capacitação para Conselheiros e Lideranças Comunitárias (pp 194-214). BrasíliaSENAD; 2011.

Da Silveira, D. X., Fidalgo, T. M., Di Pietro, M., Santos, J. G. Jr., \& Oliveira, L. Q. (2014). Is drug use related to the choice of potentially more harmful methods in suicide attempts? Substance Abuse, 8(1), 41-43.

DeBeck, K., Buxton, J.,Kerr, T., Qi, J., Montaner,J. \& Wood, E. (2011).Public crack cocaine smoking and willingness to use a supervised inhalation facilityimplications for street disorder. Substance Abuse Treatment, Prevention, and Policy, 6(4), 2-8.

De Micheli, D., Fisberg, M., \& Formigoni, M. L. O. S. (2004). Estudo da efetividade da intervenção breve para o uso de álcool e outras drogas em adolescentes atendidos num serviço de assistência primária à saúde. Revista da Associação Médica Brasileira, 50(3), 305-313. https://doi.org/10.1590/S0104- 
42302004000300040 .

Diehl, A., Cordeiro, D. C., \& Laranjeira, R. (2011). Dependência químicaPrevenção, tratamento e políticas públicas. Porto AlegreArtmed.

Dolan, S. L., Rohsenow, D. J., Martin, R. A., \& Monti, P. M. (2013). Urge-specific and lifestyle coping strategies of alcoholicsRelationships of specific strategies to treatment outcome. Drug and Alcohol Dependence, 128, 8-14.

Donovan, D. M. (2009). Avaliação dos comportamentos dependentes na prevenção da recaída. InDonovan \& Marlatt (Orgs.), Avaliação dos comportamentos dependentes (pp.1-50). São PauloRoca.

Dragisic, T., Dickov, A., Dickov, V., \& Mijatovic, V. (2015). Drug addiction as risk for suicide attempts. Materia Sociomedica, 27(3), 188-91.

Eaton, N.R., Rodrigues-Seijas, C., Krueger, R. F., Campbell, W. K., Grant, B. F., \& Hasin, D. S. (2017). Narcissistic personality disorder and the structure of common mental disorders. Journal of Personality Disorders, 31(4), 449-61.

Enfrentamento. (2020). Dicionário on-line Michaelis. http://michaelis.uol.com.br/busca?r=0\&f=0\&t=0\&palavra=ENFRENTAMENTO+

Enoch, M. (2003). Pharmacogenomics of alcohol response and addiction. American Journal of Pharmacogenomics, 3(4), $217-232$.

Félix, T., Oliveira, E., Lopes, M. V., Parente, J. R., Dias, M. S., \& Moreira, R. M. (2016). Fatores de risco para tentativa de suicídioprodução de conhecimento no Brasil. Revista Contexto \& Saúde, 16(31), 173-185. https://doi.org/10.21527/2176-7114.2016.31.173-185

Ferreira, I. B., Paiva, C; B., Narvaez, J. C. de M., \& Bosa, V. L. (2015). Estado nutricional e hábitos alimentares de dependentes químicos em tratamento ambulatorial. Jornal Brasileiro de Psiquiatria, 64(2):146-53.

Forys, K., McKellar, J., \& Moos, R. (2007). Participation in specific treatment components predicts alcohol-specific and general coping skills. Addictive Behaviors, 32(8), 1669-1680.

Fox, T. P., Oliver, G., \& Ellis, S. M. (2013). The destructive capacity of drug abuseAn overview exploring the harmful potential of drug abuse both to the individual and to society. ISRN Addiction. Article ID 450348. https://www.hindawi.com/journals/isrn/2013/450348/

Giusti, J. S. (2013). AutomutilaçãoCaracterísticas clínicas e comparação com pacientes com transtorno obsessivo compulsivo. (Tese de Doutoramento). Universidade de São Paulo, São Paulo, SP, Brasil.

Heber, D., \& Carpenter, C.L. (2011). Addictive genes and the relationship to obesity and inflammation. Molecular Neurobiology, 44(2), 160-165.

Hess, A.R.B., Almeida, R. M. M. D., \& Moraes, A. L. (2012). Comorbidades psiquiátricas em dependentes químicos em abstinência em ambiente protegido. Estudos de Psicologia, 17(1), 171-178.

Kolling, N. M., Petry, M., \& Vieira, W. (2011). Outras abordagens no tratamento da dependência do crack. Revista Brasileira de Terapia Cognitiva, 7(1), 714. : http://www.rbtc.org.br/detalhe_artigo.asp?id=134.

Lacchini, A., Ribeiro, D., Soccol, K., Terra, M., \& Silva, R. (2013). A Enfermagem e a Saúde Mental após a Reforma Psiquiátrica. Revista Contexto \& Saúde, 11(20), 565-568. https://doi.org/10.21527/2176-7114.2011.20.565-568

Laranjeira, R., Madruga, C. S., Pinsky, I., Caetano, R., Mitsuhiro, S. S., \& Castello G. (2013). II Levantamento Nacional de Álcool e Drogas (LENAD) - 2012. São PauloINPAD/UNESP. http://inpad.org.br/wp-content/uploads/2014/03/ Lenad-II-Relatório.pdf

Lei $n^{o}$ 7.498, de 25 de junho de 1986. Dispõe sobre a regulamentação do exercício da Enfermagem, e dá outras providências. http://www.planalto.gov.br/ccivil_03/LEIS/L7498.htm

Lei $n^{\circ} 10.216$, de 6 de abril de 2001. Dispõe sobre a proteção e os direitos das pessoas portadoras de transtornos mentais e redireciona o modelo assistencial em saúde mental. http://www.planalto.gov.br/ccivil_03/leis/leis_2001/110216.htm

Li, Q., Li, X., \& Stanto, B. (2010). Alcohol Use and Sexual Risk Behaviors and Outcomes in ChinaA Literature Review. AIDS Behavior, 14(6), 1227-1236.

Lima, D. D., Azevedo, R. C. S., Gaspar, K. C., Silva, V. F., Mauro, M. L. F., \& Botega, N. J.. (2010). Tentativa de suicídio entre pacientes com uso nocivo de bebidas alcoólicas internados em hospital geral. Jornal Brasileiro de Psiquiatria, 59(3), 167-172. https://dx.doi.org/10.1590/S0047-20852010000300001

Luo, X. F., Duan, S., Duan, Q. X., Pu, Y. C., Yang, Y. C., Wong, F. Y., \& He, N. (2012). Prevalence and correlates of alcohol use and subsequent sexual activity among adult males in a rural community of ethnic minorities in Yunnan Province, China. Bioscience Trends, 6(6), 288-295.

Machado, D. B., \& Santos, D. N. (2015). Suicídio no Brasil, de 2000 a 2012. Jornal Brasileiro de Psiquiatria, 64(1), 45-54.

Marcolan, J. F., \& Castro, R. C. B. R. (2013). Enfermagem em saúde mental e psiquiátricadesafios e possibilidades do novo contexto do cuidar. Rio de JaneiroElsevier.

Marcon, S. R., Xavier, J. S., Barcelon, A. A., Espinosa, M. M., \& Barbosa, D. A. (2014). Correlação entre sintomas depressivos e qualidade de vida de usuários de substâncias psicoativas. Revista da Escola de Enfermagem da USP, 48(4), 663-669.

Mars, B., Heron, J., Crane, C., Hawton, K., Lewis, G., Macleod, J., Tilling, K., \& Gunell, D. (2014). Clinical and social outcomes of adolescent self harmPopulation based birth cohort study. British Medical Journal, 349, 5954.

Matto, S.K., Chakrabarti, S., \& Anjaiah, M. (2009). Psychosocial factors associated with relapse in men with alcohol or opioid dependence. The Indian Journal of Medical Research, 130(6),702-8. 
Mazzuchello, F. R., Ceretta, L. B., Schwalm, M. T., Dagostim, V. S., \& Soratto, M. T. A atuação dos enfermeiros nos Grupos Operativos Terapêuticos na Estratégia Saúde da Família. O Mundo da Saúde, 38(4), 462-472.

Mincis, M., \& Mincis, R. (2011). Álcool e o Fígado. Gastroenterologia Endoscopia Digestiva, 30(4), 152-162

Monti, P. M., Kadden, R. M., Rohsenow, D. J., Cooney, N. L., \& Abrams, D. B. (2005). Tratando a dependência de álcoolUm guia de treinamento das habilidades de enfrentamento. São PauloRoca.

North American Nursing Diagnosis Association International (NANDA-I). (2018). Diagnósticos de enfermagem da NANDA-Idefinições e classificação 20182020. Porto AlegreArtmed.

Neale, J., Netlenton, S., Pickering, L., Fischer, J. (2012). Eating patterns among heroin usersa World Health Organization qualitative study with implications for nutritional interventions. Addiction, 107(3), 635-641.

Olivan-Blazquez, B., Rubio-Aranda, E., Garcíaz-Sanz, O., \& Magallón-Botayas, R. (2016). Correlation between diagnosis of depression and symptoms present in primary care patients. Actas Espanolas de Psiquiatria, 44(2), 55-63.

Oliveira, L. G., \& Napo, S.A. (2008). Crack na cidade de São Pauloacessibilidade, estratégias de mercado e formas de uso. Revista de Psiquiatria Clínica, 35(6), 212-8.

Orem, D. (2001). Nursingconcepts of practice. 6 th ed. St. LouisMosby -Year Book.

Otero, R. M., \& Cortés, J. R. (2008). Nutrición y alcoholismo crónico. Nutrición Hospitalaria, 23,3-7.

Pereira, A. S., Shitsuka, D. M., Parreira, F. J., \& Shitsuka, R. (2018). Metodologia da pesquisa científica. Santa MariaEd. UAB/NTE/UFSM. https://repositorio.ufsm.br/bitstream/handle/1/15824/Lic_Computacao_Metodologia-Pesquisa-Cientifica.pdf?sequence=1

Pereira, M. A. O., Machado, M. P. M., \& Nascimento, S. A. E. G. (2008). Inserção da saúde mental no Programa Saúde da Família com oficinas de sensibilizaçãorelato de experiência. Ciência e Cuidado em Saúde, 7(1), 59-64.

Pompili, M., Serafini, G., Innamorati, M., Dominici,G., Ferracuti, S., Kotzalidis, G. D., et al. (2010). Suicidal behavior and alcohol abuse. International Journal of Environment Research Public Health. 7, 1392-431. https://www.ncbi.nlm.nih.gov/pmc/articles/PMC2872355/pdf/ijerph-07-01392.pdf.

Portaria GM/MS $n^{\circ}$ 336, de 19 de fevereiro de 2002. Estabelece as diferentes modalidades de Centro de Atenção Psicossocial - CAPS. http://bvsms.saude.gov.br/bvs/saudelegis/gm/2002/prt0336_19_02_2002.html

Portaria ${ }^{\circ}$ 130, de 26 de janeiro de 2012. Redefine o Centro de Atenção Psicossocial de Álcool e outras Drogas 24 h (CAPS AD III) e os respectivos incentivos financeiros. https://bvsms.saude.gov.br/bvs/saudelegis/gm/2012/prt0130_26_01_2012.html.

Portaria $n^{\circ}$ 3.588, de 21 de dezembro de 2017. Altera as Portarias de Consolidação n ${ }^{\circ}$ 3/GM/MS e n ${ }^{\circ}$ 6/GM/MS, de 28 de setembro de 2017, para dispor sobre a Rede de Atenção Psicossocial, dá outras providências e inclui procedimentos de Tratamento em Psiquiatria na Tabela de Procedimentos, Medicamentos, Órteses, Próteses e Materiais Especiais do SUS. http://bvsms.saude.gov.br/bvs/saudelegis/gm/2017/prt3588_22_12_2017.html

Reis, L. M., Sales, C. A., \& Oliveira, M. L. F. (2017). Narrative of a drug user's daughterimpact on family daily routine. Escola Anna Nery, 21(3), e20170080. : http://www.scielo.br/pdf/ean/v21n3/1414-8145-ean-2177-9465-EAN-2017-0080.pdf.

Resolução COFEN $n^{\circ}$ 358/2009, de 15 de outubro de 2009. Dispõe sobre a Sistematização da Assistência de Enfermagem e a implementação do Processo de Enfermagem em ambientes, públicos ou privados, em que ocorre o cuidado profissional de Enfermagem, e dá outras providências. http// www.portalcofen.gov

Resolução $n^{\circ}$ 599/2018. Aprova a Norma Técnica para Atuação da Equipe de Enfermagem em Saúde Mental e Psiquiatria. http://www.cofen.gov.br/resolucaocofen-no-599-2018_67820.html. Acesso em 05 jun 2020.

Ribeiro, D.B. (2012). Motivos da tentativa de suicídio expressos por homens usuários de álcool e outras drogas. (Dissertação). Universidade Federal de Santa Maria, Santa Maria, RS, Brasil.

Ribeiro, D. R., Carvalho, D. S. (2016). Associação entre o estado nutricional e padrões de uso de drogas em pacientes atendidos em Centros de Atenção Psicossocial Álcool e Drogas. SMAD, Revista Eletrônica Saúde Mental Álcool Drogas. 12(2), 92-100.

Rodrigues, T. F. C. S., Sanches, R. C. N., Oliveira, M. L. F., Pinho, L. B., \& Radovanovic, C. A. T. (2018). Sentimentos de famílias na dependência de drogasà luz da sociologia compreensiva. Revista Brasileira de Enfermagem, 71(Suppl. 5), 2272-2279. https://www.scielo.br/scielo.php?pid=S0034$71672018001102272 \&$ script=sci_arttext\&tlng=pt

Saatcioglu, O., Yapici, A., \& Cakmak, D. (2008). Quality of life, depression and anxiety in alcohol dependence. Drug and Alcohol Review, 27(1), 83-90.

Saeland, M., Haugen, M., Eriksen, F. L., Wandel, M., Smehaugen, A., Bömer, T, et al. (2022). High sugar consumption and poor nutrient intake among drug addicts in Oslo, Norway. The British Journal of Nutrition, 105(4), 618-24

Santos, R. B, (2014). Prevalência e fatores associados à infecção pelo HIV entre usuários de drogas lícitas e ilícitas. (Dissertação). Programa de Pós-Graduação em Ciências da Saúde da Universidade Federal de Pernambuco, Recife, PE, Brasil.

Scheffer, M., Passa, G. G., \& Almeida, R.M. (2010). Dependência de álcool, cocaína e crack e transtornos psiquiátricos. PsicologiaTeoria e Pesquisa, 26(3), 533-541.

Silva, M.R.S., Lunardi, V. L., Lunardi, W. D. F., \& Tavares, K. O. (2005). Resiliência e promoção da saúde. Texto \& contexto Enfermagem,14(esp), 95-102. 
Research, Society and Development, v. 10, n. 2, e10310212160, 2021

(CC BY 4.0) | ISSN 2525-3409 | DOI: http://dx.doi.org/10.33448/rsd-v10i2.12160

http://www.scielo.br/pdf/tce/v14nspe/a11v14nspe.pdf

Sinha, R. (2009). Modeling stress and drug craving in the laboratoryImplications for addiction treatment development. Addiction Biology, 14(1), 84-98.

Smith, S. M., Goldsteins,R. B., \& Grant, B.F. (2016). The association between post-traumatic stress disorder and lifetime DSM-5 psychiatric disorders among veteransData from the National Epidemiologic Survey on Alcohol and Related Conditions-III (NESARC-III). Journal of Psychiatric Research, 82(11), 16-22.

Souza, M.C.H de. (2015). Estudo das habilidades de enfrentamento e da autoeficácia para a abstinência em dependentes de crack. (Dissertação). Programa de Pós-Graduação em Psicologia. Pontifícia Universidade Católica do Rio Grande do Sul, Porto Alegre, RS, Brasil. http://tede2.pucrs.br/tede2/handle/tede/6340?mode=full

Staiger, P. K., Thomas, A. C., Ricciardelli, L. A., \& McCabe, M. P. (2011). Identifying depression and anxiety disorders in people presenting for substance use treatment. Medical Journal of Australia, 195(3). : https://www.mja.com.au/system/files/issues/195_03_010811/sta10926_fm.pdf.

Tang, A. M., Bhatnagar, T.; Ramachandran, R., Dong, K., Skinner, S., Kumar, M. S., \& Wanke, C. A. (2011). Malnutrition in a population of HIV-positive and HIV-negative drug users living in Chennai, South India. Drug and Alcohol Dependence, 118(1), 73-7.

Tavares, R. C., \& Sousa, S. M. G. (2009). Os Centros de Atenção Psicossocial e as possibilidades de inovação das práticas em saúde mental. Saúde em Debate, $33(82), 252-263$.

Teixeira, G. A., Carvalho, J. B. L., Silva, A. L. M. A., Santos, S. B., \& Lopes, T. R. G. (2015). Sistematização da Assistência de Enfermagem a pessoa em situação de rua. Revista de Enfermagem UFPE on line., 9(3), 7169-7174. https://periodicos.ufpe.br/revistas/revistaenfermagem/article/view/10448/11263

Ti, L., Buxton, J., Wood, E., Zhang, R., Montaner, J., \& Kerr, T. (2011). Difficulty accessing crack pipes and crack pipe sharing among people who use drugs in Vancouver, Canada. Substance Abuse Treatment, Prevention, and Policy, 6(34), 2-5

Vinadé, T. F. (2009). Redução de danos na atenção primária à saúdeconstruindo a potência do encontro. In F. Minozzo \& $\mathrm{S}$. P. França (orgs.), A detecção $e$ o atendimento a pessoas usuárias de drogas na rede da Atenção Primária à Saúdemódulo 7. BrasíliaSecretaria Nacional de Políticas sobre drogas. 